\title{
Bacterial culture and immunohistochemical detection of bacteria and endotoxin in cats with suppurative cholangitis-cholangiohepatitis syndrome
}

\author{
Sharon A. Center, DVM¹*; John F. Randolph, DVM'; Karen L. Warner, BS; Sean P. McDonough, DVM, PhD²; \\ John M. Lucy, DVM³; Kirk C. Sapa ${ }^{1}$

\begin{abstract}
1Department of Clinical Sciences, College of Veterinary Medicine, Cornell University, Ithaca, NY
2Department of Biomedical Sciences, College of Veterinary Medicine, Cornell University, Ithaca, NY

${ }^{3}$ Oradell Animal Hospital, Paramus, NJ
\end{abstract} \\ ${ }^{*}$ Corresponding author: Dr. Center (sac6@cornell.edu)
}

https://doi.org/10.2460/javma.20.10.0552

\section{OBJECTIVE}

To characterize the frequency and type of bacterial infection by culture- and immunohistochemical (IHC)-based methods and determine the impact of infection on clinical features and survival time in cats with suppurative cholangitis-cholangiohepatitis syndrome (S-CCHS).

\author{
ANIMALS \\ 168 client-owned cats with S-CCHS (cases).
}

\section{PROCEDURES}

Clinical features, bacterial culture results, culture-inoculate sources, and survival details were recorded. Cases were subcategorized by comorbidity (extrahepatic bile duct obstruction, cholelithiasis, cholecystitis, ductal plate malformation, biopsy-confirmed inflammatory bowel disease, and biopsy-confirmed pancreatitis) or treatment by cholecystectomy or cholecystoenterostomy. Culture results, bacterial isolates, Gram-stain characteristics, and IHC staining were compared among comorbidities. Lipoteichoic acid IHC staining detected gram-positive bacterial cell wall components, and toll-like receptor expression IHC reflected pathologic endotoxin (gram-negative bacteria) exposure.

\section{RESULTS}

Clinical features were similar among cases except for more frequent abdominal pain and lethargy in cats with positive culture results and pyrexia, abdominal pain, and hepatomegaly for cats with polymicrobial infections. Bacteria were cultured in 93 of 135 (69\%) cats, with common isolates including Enterococcus spp and Escherichia coli. IHC staining was positive in 142 of 151 (94\%) cats (lipoteichoic acid, 107/142 [75\%]; toll-like receptor 4, 99/142 [70\%]). With in-parallel interpretation of culture and IHC-based bacterial detection, 154 of 166 (93\%) cats had bacterial infections (gram-positive, 118/154 [77\%]; gram-negative, 111/154 [72\%]; polymicrobial, $79 / 154$ [51\%]). Greater frequency of bacterial isolation occurred with combined tissue, bile, and crushed cholelith inoculates. Infection and gram-positive bacterial isolates were associated with significantly shorter long-term survival times.

\section{CLINICAL RELEVANCE}

S-CCHS was associated with bacterial infection, pathologic endotoxin exposure, and frequent polymicrobial infection in cats. Combined tissue inoculates improved culture detection of associated bacteria.

$\mathbf{S}$ uppurative cholangitis or cholangiohepatitis often develops in cats with comorbidities that predispose to bile-borne bacterial infection. ${ }^{1}$ These comorbidities, as well as clinical features, clinicopathologic findings, and survival, are detailed in a large number of cats with suppurative cholangitis-cholangiohepatitis syndrome (S-CCHS) in the companion report. ${ }^{1}$ To date, culture or molecular methods of bacterial detection in small numbers of cats support that at least a subset of cats with S-CCHS or obstructive cholangiopathies have bacterial infection. ${ }^{2-22}$ However, detection of bacteria by culture may be compromised by the common practice of administering broad-spectrum antimicrobials before sample collection.1,11,14 Conversely, highly sensitive molecular methods for bacterial detection such as fluorescent in situ hybridization or PCR assay increase the likelihood of detecting nonrelevant bacteria undergoing enterohepatic transit or tissue contaminants. ${ }^{19,23}$ Thus, a sensitive method with lower risk for detection of nonrelevant bacteria in cats with S-CCHS would be informative for understanding the involvement of bacteria in this syndrome. 
We hypothesized that lipoteichoic acid (LTA [a cell wall component in gram-positive bacteria]) and pathologic expression of toll-like receptor 4 (TLR-4 [reflecting pathologic gram-negative bacterial exposure]) as detected by immunohistochemical (IHC) staining might function as relevant markers of bacterial infection. Lipoteichoic acid is a strongly immunogenic surface reactive antigen that mediates attachment of gram-positive bacteria to host cells. ${ }^{24-29}$ Residual LTA has also been proposed as a mechanistically pathogenic factor in some forms of chronic cholangitis in humans and animals with experimentally induced disease. ${ }^{27-29}$ Expression of TLR-4, a pathogen pattern recognition receptor, reflects pathologic exposure to gram-negative bacterial lipopolysaccharide (LPS [or endotoxin]) and is considered more relevant to disease pathogenesis than detection of lipid-A (biologically active component of LPS). ${ }^{30-35}$ Because endotoxin commonly circulates to the liver in the portal circulation and is removed by hepatic Kupffer cells and sinusoidal endothelium, detection of lipid-A alone does not necessarily reflect a pathologic response. ${ }^{31-33,35-38}$ In health, tolerance to minor but constant enterohepatic LPS or endotoxin exposure downregulates TLR-4 expression, whereas pathologic exposure provokes TLR-4 upregulation. ${ }^{32,33}$

The present study was undertaken to investigate the association of bacterial infection with S-CCHS in cats, comparing culture-based detection of bacteria in liver, bile, gallbladder, and choleliths to IHCdetected LTA and TLR-4 expression.

\section{Materials and Methods}

\section{Case selection criteria}

Cats with S-CCHS were identified by liver biopsy, and clinical data were prospectively cataloged at the time of diagnosis over a 40-year interval (1980 to 2019) by one of the authors (SAC). Details regarding liver sample collection and processing are reported elsewhere. ${ }^{1}$ All tissue sections were initially inspected by board-certified veterinary anatomic pathologists and pathology residents-in-training and were also independently reviewed by 2 of the authors (SAC and SPM) naïve to case details before data entry to verify histologic characterization. Diagnosis of S-CCHS required predominant portal neutrophilic infiltrates demonstrating a duct-centric orientation, with or without features consistent with extrahepatic bile duct obstruction (EHBDO), cholangiocyte proliferation (ductular reaction), destructive cholangitis (ie, necrotic duct epithelium, irregular duct epithelial stratification or attenuation, and duct collapse or involution), or invasion of the limiting plate by inflammatory infiltrates. Although an attempt was made to apply a previously recommended histologic classification method discriminating between acute and chronic S-CCHS in cats, intraindividual variation among liver sections confounded this effort, similar to previously published observations. 39,40 Definitive disease group categorization was assigned after reconciling histologic features and clinical information that included historical and physical examination findings, results of diagnostic imaging, and gross observations at surgery or necropsy.

\section{Medical record review}

Clinical records of cats meeting histologic inclusion criteria of S-CCHS were reviewed with pet caretakers and referring veterinarians, as needed, to clarify pre- and postbiopsy treatments, postbiopsy health status, and survival status. An organizational spreadsheet was used to standardized data collection, which included signalment, clinical signs, antecedent or concurrent illness, physical examination findings, and results of clinicopathologic tests, imaging studies, and surgery. ${ }^{1}$ Results of aerobic and anaerobic bacterial cultures (for samples of liver, gallbladder or common bile duct bile, gallbladder wall, choledochal cyst fluid, or crushed choleliths), treatments (antecedent and postoperative antimicrobials, antecedent glucocorticoid drugs, or other immunosuppressant medications), and survival time after definitive diagnosis (days after definitive diagnosis and age at death) were transcribed. Cats with S-CCHS were subcategorized into designated comorbidities ${ }^{1}$ including EHBDO, cholelithiasis, cholecystitis, ductal plate malformation (DPM), diabetes mellitus, biopsy-confirmed inflammatory bowel disease (IBD), and biopsy-confirmed pancreatitis and treatment interventions including cholecystectomy and cholecystoenterostomy.

\section{Histologic criteria defining comorbidities}

Diagnosis of EHBDO required distention of medium- and large-sized bile ducts with or without evidence of bile duct tortuosity, variable intraluminal biliary debris (mucin or bile-stained secretions and exfoliated epithelial or inflammatory cells), periductal edematous laminating fibrosis, periductal neutrophilic or neutrophilic mixed inflammatory infiltrates, hyperplasia of small bile ducts, and dimensional expansion of portal tracts with edematous extracellular matrix. Ultrasound imaging or gross inspection of extrahepatic biliary structures during surgery or at necropsy confirmed EHBDO in all cases in this category. Diagnosis of cholecystitis required examination of gallbladder sections confirming neutrophilic or mixed inflammatory mural infiltrates, with variable mural edema, hemorrhage or fibrosis, intraluminal inflammatory cells, or biliary concretions (microcholeliths), hemobilia, or bacteria. Gram staining of gallbladder sections was completed in 18 cats. Diagnosis of cholecystitis was reconciled with ultrasound images of the gallbladder and its gross appearance during surgery or necropsy. Diagnosis of DPM was based on finding the characteristic morphology of syndrome phenotypes, as specified in the companion report ${ }^{1}$ and recently described in 2 other reports. ${ }^{41,42}$ Pancreatitis was diagnosed histologically on the basis of finding interstitial or periductal suppurative, Iymphocytic, or lymphoplasmacytic inflammatory infiltrates. Diagnosis of IBD was based on evaluation of full-thickness intestinal biopsy specimens with consideration given to the inflammatory cellular population as well as degree 
and distribution of inflammatory infiltrates, presence of intraepithelial lymphocytes, villi length, villi fusion, epithelial cell injury, lacteal dilation, and intestinal crypt depth, tortuosity (hyperplasia), distention, and dropout, and estimated fibrosis (lamina propria of villi and between crypts). ${ }^{43}$

\section{IHC staining}

Immunohistochemical staining for LTA and TLR-4 was completed on liver sections from 151 of 168 (90\%) cats with S-CCHS (cases) and 20 cats lacking necroinflammatory liver disease (controls). Controls included clinically healthy cats from unrelated projects $(n=7)$, cats with congenital portosystemic vascular anomalies (3), cats with hepatic lipidosis (2), cats that died unexpectedly during routine ovariohysterectomy (2), and cats that had liver samples collected during exploratory laparotomy for chronic cystitis (1), chronic gastritis (1), or vomiting related to suspected IBD (1) or immediately after euthanasia because of bacterial otitis and meningitis (1), cardiac disease (1), or noninfectious renal failure (1). Details regarding IHC staining protocols are provided (Supplementary Appendix S1). Negative control slides (processed with primary antibody replaced with a species-matched nonreactive IgG at equivalent concentrations) and positive control slides for LTA (culture-confirmed Streptococcus abscess in a cat) and TLR-4 (liver, spleen, and mesenteric lymph node from a cat with disseminated Escherichia coli) were routinely included.

Localization of TLR-4 expression was verified by prominent staining in inflammatory cells (ie, neutrophils, Iymphocytes, and local macrophages) within or adjacent to portal tracts, biliary epithelium of medium- to large-sized bile ducts, and gallbladder, with rare staining in hepatocytes and regional Kupffer cells. Then sections were evaluated in $10 \mathrm{mi}-$ croscopic fields of view at 100X and 200X magnification. Semiquantitative scores (0 to 3 ) were assigned to characterize TLR-4 expression reflecting the percentage of inflammatory cells and biliary epithelium with positive staining. Per this scoring system, 0 indicated no IHC positivity; 1 indicated rare positive cells (ie, $\leq 10 \%$ inflammatory cells, macrophages, or biliary epithelium); 2 indicated > 10\% but < 50\% positive inflammatory cells, macrophages, or biliary epithelium; and 3 indicated $\geq 50 \%$ positive inflammatory cells, macrophages, or biliary epithelium. The types of cells staining positively and their zonal distribution were recorded. For LTA, results were summated as positive or negative for the tissue examined (ie, liver, gallbladder, common bile duct, choledochal cyst wall, or cholelith) and defined as rare single organisms or clusters, chains, or mats of bacteria.

\section{In-parallel detection of bacteria by combined interpretation of culture and IHC staining}

Bacterial isolates were recorded by genus (ie, not all bacteria were speciated) and organized into categories of aerobic or facultative anaerobic and fastidious anaerobic organisms and gram-positive or gram-negative staining. The number of cats with culture-based single and polymicrobial infections was determined. The number of infecting organisms in polymicrobial infections was cataloged. The number of cats with IHC detected gram-positive (LTA IHC positive) or gram-negative (TLR-4 IHC positive) infections and those with both gram-positive and gram-negative infections (ie, LTA IHC positive and TLR-4 IHC positive) were enumerated. Dually positive LTA and TLR-4 IHC samples were deemed IHC polymicrobial even though such classification underestimated polymicrobial status because it could not differentiate multiple different gram-positive or multiple different gram-negative organisms. Frequency of gram-positive or gram-negative bacterial detection by culture and IHC methods was enumerated, and concordance was determined. In-parallel interpretation of culture and $\mathrm{IHC}$ test results was used to estimate the maximum number of cats with bacterial infections, gram-positive infections, gram-negative infections, and polymicrobial infections (acknowledging that IHC-detected polymicrobial infection underestimated polymicrobial infections). ${ }^{44}$ In-parallel test interpretation declared a cat infected if it had either a positive culture or positive IHC staining result. This in-parallel strategy was used to minimize false negative test results.

\section{Single and combined inoculate cultures}

The number of inoculate sources for bacterial culture from each cat was enumerated. Samples were designated as combined inoculates if they had 2 or more different origins (eg, liver, bile, gallbladder wall, choleliths, or fluid from cystic malformations). The frequency of positive culture results with single or combined inoculates was also recorded.

\section{Statistical analysis}

Data on cat signalment, an absence of sex or breed predilection, spectrum of clinicopathologic abnormalities, and survival status (without details of bacterial infections described herein) are provided in the companion report. ${ }^{1}$

Because most numerical data were nonparametric, details are reported as median (range) and 95\% Cls. The criterion for a positive in-parallel test result required that either test result be abnormal (ie, positive culture or IHC staining result) to avoid false negative results. ${ }^{44}$ The influence of culturebased, IHC-based, and in-parallel test detection of bacterial infection, gram-positive and gram-negative infection, and polymicrobial infection on clinical features was evaluated by use of $2 \times 2$ tables and the Fisher exact test. Duration of antecedent clinical illness (days) and WBC count, neutrophil count, fold increase of serum liver enzyme activities, and serum total bilirubin concentrations were compared between cats with and without bacterial infection as deemed by culture, IHC, and in-parallel testing in all cats, cats within each comorbidity group, cats with and without cholecystectomy, cats with and without cholecystoenterostomy, and cats with polymicrobial versus single isolate infections by means of the 
Wilcoxon rank sum test. The fold increases in liver enzyme activity and total bilirubin concentration were normalized using the upper limit of the reference interval validated for the relevant analytic method. Prevalences were calculated for bacterial infection and gram-positive, gram-negative, aerobic, anaerobic, and polymicrobial isolates among all cats and cats within comorbidity groups. The frequency of bacterial isolation by culture and the number of bacterial isolates per cat from single and combined inoculates were compared using $2 \times 2$ tables and the Fisher exact test. Differences in the number of aerobic or facultative anaerobic and fastidious anaerobic isolates, proportion of gram-positive cultured isolates versus LTA IHC-positive results, and proportion of gram-negative cultured isolates versus TLR-4 IHCpositive results and culture-based aerobic or facultative anaerobic and fastidious anaerobic isolates were evaluated for cats with single and polymicrobial bacterial infections using $2 \times 2$ tables and the Fisher exact test.

Survival times were computed for cats with and without bacterial infection and single versus polymicrobial infection for culture-based, IHC-based, and inparallel test results by means of Kaplan Meier statistics (survival time in days after definitive diagnosis and age at death). The Gehan-Wilcoxon test (short-term survival) and log-rank test (long-term survival) were performed to identify significant $(P \leq 0.05)$ differences between groups. Discordance and concordance between culture-based and IHC-based bacterial detection were determined and expressed as a percentage. Statistical analyses were performed with a statistical software program (Statistix 9; Analytical Software).

\section{Results}

\section{Bacterial culture}

Of 168 cats, 135 (80\%) had samples submitted for bacterial culture. Of these, 93 (69\%) were positive despite common administration of broad-spectrum antimicrobials for several days (sometimes weeks) before culture sample collection.

Among comorbidities, frequencies of bacterial culture submission ranged from $82 \%$ to $90 \%$ of cats, and frequencies of positive results ranged from 63\% to $78 \%$ (Table 1). Origins of culture inoculates included liver $(n=119)$, gallbladder bile (90), choledochal cyst fluid (8), crushed cholelith (10), and gallbladder mucosal scrape or wall section (15). There were fewer single inoculates $(n=52)$ than combined inoculates (83). Origins of single inoculates included liver $(n=40)$, gallbladder bile (9), common bile duct bile (1), and crushed cholelith (2). Combined inoculates commonly included liver and gallbladder bile (54/83 [65\%]), but also included combinations of liver, bile, and gallbladder wall with or without gallbladder mucosal scrapings (14); liver, bile, and crushed cholelith (4); liver and crushed cholelith (2); bile and crushed cholelith (1); bile and choledochal cyst contents (3); liver, bile, and choledochal cyst contents (4); and liver, bile, choledochal cyst contents, and crushed cholelith (1). Bile often was centrifuged in a sterile vial with bile sediment used as the submitted inoculate. Gram staining of gallbladder sections from 18 cats disclosed gram-positive bacteria in only $3(17 \%)$. Significantly $(P<0.001)$ more positive cultures were detected with combined inoculates (68/83 [82\%]) than with single inoculates (25/52 [48\%]). Among 41 cats with culture-based polymicrobial infections, 2 organisms were involved in 27 (66\%), 3 organisms in $11(27 \%)$, and $\geq 4$ organisms in $3(7 \%)$. One cat with chronic extracorporeal bile drainage had 7 bacterial pathogens isolated from bile. A significantly $(P$ $<0.001$ ) greater number of polymicrobial infections were diagnosed from combined inoculates (33/41 [80\%]) than with single inoculates $(8 / 41[20 \%])$.

Of 93 cats with positive cultures, 69 (74\%) had aerobic/facultative anaerobic isolates, 25 (27\%) had fastidious anaerobic isolates, and 41 (44\%) were polymicrobial. Among positive cultures, the frequency of gram-positive and gram-negative isolates was not significantly different (Table 1); however, aerobic or facultative anaerobic isolates $(n=109)$ were significantly $(P<0.001)$ more common than fastidious anaerobic isolates (30; Supplementary Table S1). Single-isolate infections (52/93 [56\%]) were not significantly more common than polymicrobial infections (41/93 [44\%]). Common aerobic or facultative anaerobic isolates included $E$ coli $(n=41$; $44 \%$ of positive cultures) and Enterococcus ( $n=36$; $39 \%$ of positive cultures). These organisms also were common in polymicrobial infections (Enterococcus [12/41 \{29\%\}]; E coli [6/41 \{15\%\}]). Among polymicrobial infections, 37 of $41(90 \%)$ involved mixed gram-positive and gram-negative isolates, with 4

Table 1-Results of bacterial culture for cats with suppurative cholangitis-cholangiohepatitis syndrome (S-CCHS)

\begin{tabular}{lcccccc} 
Group & $\begin{array}{c}\text { Total No. } \\
\text { of cats }\end{array}$ & $\begin{array}{c}\text { No. of cats with } \\
\text { bacterial culture }\end{array}$ & $\begin{array}{c}\text { Positive } \\
\text { culture }\end{array}$ & $\begin{array}{c}\text { Gram+ } \\
\text { isolates }\end{array}$ & $\begin{array}{c}\text { Gram- } \\
\text { isolates }\end{array}$ & $\begin{array}{c}\text { Polymicrobial } \\
\text { isolates }\end{array}$ \\
\hline All cats with S-CCHS & 168 & $135(80)$ & $93(69)$ & $72(77)$ & $67(72)$ & $41(44)$ \\
EHBDO & 89 & $73(82)$ & $54(74)$ & $42(78)$ & $37(69)$ & $26(48)$ \\
Cholelithiasis & 71 & $62(87)$ & $44(71)$ & $35(80)$ & $31(71)$ & $23(52)$ \\
Cholecystitis & 68 & $58(85)$ & $45(78)$ & $36(80)$ & $32(71)$ & $25(56)$ \\
Cholecystectomy & 39 & $35(90)$ & $27(77)$ & $20(74)$ & $19(70)$ & $13(48)$ \\
Cholecystoenterostomy & 37 & $33(89)$ & $21(64)$ & $18(86)$ & $15(71)$ & $12(57)$ \\
Ductal plate malformation & 74 & $62(84)$ & $39(63)$ & $29(74)$ & $26(67)$ & $18(46)$ \\
Biopsy-confirmed IBD & 60 & $52(87)$ & $39(75)$ & $31(80)$ & $23(59)$ & $17(44)$ \\
Biopsy-confirmed pancreatitis & 41 & $35(85)$ & $27(77)$ & $18(67)$ & $21(78)$ & $14(52)$ \\
\hline
\end{tabular}

$\mathrm{EHBDO}=$ Extrahepatic bile duct obstruction. IBD = Inflammatory bowel disease. 
cats having only gram-negative isolates. Fastidious anaerobic bacteria were isolated only from cats with polymicrobial infections. The most common fastidious anaerobic isolates were Bacteroides spp $(n=10$; $11 \%$ positive cultures) and Clostridium spp ( $n=7 ; 8 \%$ positive cultures).

Among 69 cats with aerobic or facultative anaerobic infections, 38 (55\%) had EHBDO, 31 (45\%) had cholelithiasis, 31 (45\%) had cholecystitis, 30 (44\%) had DPM, 29 (42\%) had IBD, 18 (26\%) had pancreatitis, and
6 (9\%) had diabetes mellitus; 9 of 69 (28\%) cats had polymicrobial infections. Among 25 cats with fastidious anaerobic isolates, 16 (64\%) had EHBDO, 13 (52\%) had cholecystitis, 13 (52\%) had cholelithiasis, 9 (36\%) had DPM, and none had diabetes mellitus. Among cats with biopsy-confirmed IBD, 75\% had positive cultures; 39 positive cultures included 23 (59\%) gramnegative, 31 (80\%) gram-positive, and 17 (44\%) polymicrobial isolates. Bacterial isolates from 39 positive cultures included 17 (44\%) E coli and 16 (41\%) En-

Table 2-Clinical features of cats with S-CCHS stratified by bacterial culture results, Gram-staining characteristics, infection type, and immunohistochemical (IHC) results.

\begin{tabular}{|c|c|c|c|c|c|c|c|c|c|c|}
\hline Category & Pyrexia & $\begin{array}{l}\text { Abdominal } \\
\text { pain }\end{array}$ & Jaundice & Lethargy & Hyporexia & Emesis & $\begin{array}{l}\text { Weight } \\
\text { loss }\end{array}$ & Diarrhea & $\begin{array}{l}\text { Large } \\
\text { liver }\end{array}$ & $\begin{array}{c}\text { Diabetes } \\
\text { mellitus } \\
\end{array}$ \\
\hline Bacterial culture $(n=135)$ & $61(45)$ & $37 \ddagger(27)$ & $94(70)$ & 09 (81) & $111(82)$ & $114(84)$ & $73(54)$ & $29(21)$ & $46 \ddagger(34)$ & $11(8)$ \\
\hline lo bacterial culture $(n=33)$ & $13(39)$ & $1 \ddagger(3)$ & $21(64)$ & $24(73)$ & $27(82)$ & $24(73)$ & $18(55)$ & $3(9)$ & $1 \ddagger(3)$ & $0(0)$ \\
\hline Culture positive $(n=93)$ & $45(48)$ & $31^{*}(33)$ & $62(67)$ & $81^{\dagger}(87)$ & $80(86)$ & $80(86)$ & $53(57)$ & $23(25)$ & $32(34)$ & $6(6)$ \\
\hline Culture negative $(n=42)$ & $16(38)$ & $6^{*}(14)$ & $32(76)$ & $28^{+}(67)$ & $34(81)$ & $32(76)$ & $20(48)$ & $6(14)$ & $14(33)$ & $6(14)$ \\
\hline ram-positive $(n=72)$ & $36(50)$ & $26(36)$ & $50(69)$ & $62(86)$ & $62(86)$ & $62(86)$ & $43(60)$ & $18(25)$ & $26(36)$ & $5(7)$ \\
\hline$m$-negative $(n=67)$ & $32(48)$ & $24(36)$ & $39(58)$ & $55(82)$ & $50(75)$ & $53(79)$ & $34(51)$ & $15(22)$ & $25(37)$ & $3(5)$ \\
\hline le organism infection & $20 *(38)$ & $10^{+}(19)$ & $32(62)$ & $44(85)$ & $48(92)$ & $43(83)$ & $30(58)$ & 7) & $13 *(25)$ & $4(8)$ \\
\hline Polymicrobial infection ( $\mathrm{n}$ & $*(61)$ & $21^{+}(51)$ & $30(73)$ & $37(9$ & $32(78$ & 37( & $23(56)$ & $9(22)$ & $19 *(46)$ & $2(5)$ \\
\hline $\mathrm{HC}$ & & ) & 102 & ) & & & 80 & & 50 & \\
\hline 17) & 7 (41) & $2(12)$ & 11 & 3) & 15 & $13(76)$ & 10 & 4 & $7(41)$ & $1(6)$ \\
\hline itive $(n=142)$ & $63(44)$ & $35(25)$ & $94(66)$ & $118(83)$ & $116(82)$ & $113(80)$ & $76(54)$ & $26(18)$ & 47 (33) & $13(9)$ \\
\hline ative $(n=9)$ & $3(33)$ & $2(22)$ & $8(89)$ & $7(78)$ & $7(78)$ & $8(89)$ & $4(44)$ & $2(22)$ & $3(33)$ & $0(0)$ \\
\hline LTA IHC positive $(n=107)$ & $50(47)$ & $30(28)$ & $74(69)$ & $90(84)$ & $88(82)$ & $86(80)$ & $59(55)$ & $23(21)$ & $36(34)$ & $12(11)$ \\
\hline TLR-4 IHC positive $(n=99)$ & $35(35)$ & $28(28)$ & $67(68)$ & $84(85)$ & $77(78)$ & $78(79)$ & $55(56)$ & $16(16)$ & $39(39)$ & $8(8)$ \\
\hline $\begin{array}{l}\text { LTA IHC positive and TLR-4 IHC } \\
\text { positive }(n=64)\end{array}$ & $32(50)$ & $23(36)$ & 47( & 56 & 49 & $51(80)$ & 38 & 13 & $28(44)$ & $7(11)$ \\
\hline In-parallel testing: positive $(n=154)$ & $68(44)$ & $37^{*}(24)$ & $102(66)$ & $127+(83)$ & $126(82)$ & $124(81)$ & $84(55)$ & $30(20)$ & $51(33)$ & $14(9)$ \\
\hline In-parallel testing: negative $(n=12)$ & $5(42)$ & $2(17)$ & $10(83)$ & $6^{+* *}(50)$ & $10(83)$ & $9(75)$ & $4(33)$ & $2(17)$ & $5(42)$ & $0(0)$ \\
\hline In-parallel testing: polymicrobial $(n=79)$ & $42(53)$ & $29 *(37)$ & $56(71)$ & $70^{* *}(89)$ & $62(79)$ & $65(82)$ & 48 (61) & $19(24)$ & $33(42)$ & $8(10)$ \\
\hline
\end{tabular}

LTA = Lipoteichoic acid. TLR-4 = Toll-like receptor -4 .

${ }^{*} P=0.05 .{ }^{* *} P=0.03 .{ }^{\dagger} P<0.01 . \ddagger P \leq 0.0001$.

Table 3-Survival duration and age at death for cats with S-CCHS stratified by presence or absence of bacterial culture, bacterial culture results, IHC findings, and in-parallel interpretation of culture and IHC findings.

Survival (d)

after definitive diagnosis

\begin{tabular}{|c|c|c|c|c|c|c|}
\hline \multirow{2}{*}{ Category } & & \\
\hline & Median & Range & $95 \% \mathrm{Cl}$ & Median & Range & $95 \% \mathrm{Cl}$ \\
\hline Bacterial cultures $(n=135)$ & $368^{+}$ & $1-4,015$ & $592-886$ & 11.3 & $0.5-20.0$ & $10.3-11.9$ \\
\hline No bacterial cultures $(n=33)$ & $25^{\dagger}$ & $1-4,563$ & $114-718$ & 11.0 & $0.6-20.1$ & $8.8-12.2$ \\
\hline Positive cultures $(n=93)$ & 365 & $1-3,468$ & $557-915$ & 11.9 & $0.7-20.5$ & $10.5-12.3$ \\
\hline Negative cultures $(n=42)$ & 490 & $2-4,015$ & 464-992 & 10.1 & $0.5-19.0$ & $8.8-11.7$ \\
\hline Gram positive $(n=72)$ & 283 & $1-3,468$ & $500-910$ & 11.3 & $0.7-20.5$ & $10.0-12.1$ \\
\hline Gram negative $(n=67)$ & 365 & $1-3,285$ & $487-935$ & 11.6 & $0.7-10.0$ & $10.2-12.5$ \\
\hline Polymicrobial culture $(n=41)$ & 275 & $1-3,285$ & $377-928$ & 11.2 & $0.7-18.0$ & $9.5-12.2$ \\
\hline $\mathrm{IHC}(\mathrm{n}=151)$ & 330 & $1-4,563$ & $556-845$ & 11.1 & $0.5-20.5$ & $10.2-11.7$ \\
\hline Positive IHC $(n=142)$ & 329 & $1-4,563$ & $510-786$ & 11.1 & $0.5-20.5$ & $10.2-11.7$ \\
\hline Negative IHC $(\mathrm{n}=9)$ & 1,460 & $4-4,015$ & $411-2,650$ & 12.1 & $4.0-19.0$ & $7.4-15.6$ \\
\hline LTA positive $(n=107)$ & 292 & $1-4,563$ & $453-766$ & 11.0 & $0.5-20.5$ & $9.8-11.5$ \\
\hline TLR-4 positive $(n=99)$ & 365 & $1-4,563$ & $512-859$ & 11.1 & $0.6-20.5$ & $10.2-12.1$ \\
\hline IHC polymicrobial $(n=64)$ & 348 & $1-4,563$ & $425-859$ & 11.1 & $0.6-20.5$ & $9.6-12.0$ \\
\hline In-parallel testing: culture and IHC $(n=166)$ & 330 & $1-4,563$ & $550-817$ & 11.2 & $0.5-20.5$ & $10.3-11.7$ \\
\hline Positive in-parallel testing $(n=154)$ & 329 & $1-4,563$ & $527-792$ & 11.2 & $0.5-20.5$ & $10.4-11.8$ \\
\hline Negative in-parallel testing $(n=12)$ & 556 & $4-4,015$ & $204-1,789$ & 6.3 & $4.0-19.0$ & $6.1-12.7$ \\
\hline Gram-positive \pm LTA positive $(n=118)$ & 310 & $1-4,563$ & $494-806$ & 11.1 & $0.5-20.5$ & $10.0-11.7$ \\
\hline Gram-negative \pm TLR- 4 positive $(n=111)$ & 348 & $1-4,563$ & $505-827$ & 11.2 & $0.6-20.5$ & $10.5-12.2$ \\
\hline Polymicrobial: culture or IHC $(n=79)$ & 330 & $1-4,563$ & $464-868$ & 11.2 & $0.6-20.5$ & $10.1-12.2$ \\
\hline
\end{tabular}

$+P=0.0007$.

See Table 2 for remainder of key. 
terococcus spp. Among 100 cats without enteric biopsies, positive cultures in 47 of 75 (63\%) included 41 (87\%) gram-positive, 44 (94\%) gram-negative, and 21 (45\%) polymicrobial isolates. Bacterial isolates from 47 positive cultures included 24 (51\%) E coli and 20 (43\%) Enterococcus spp. There were no significant differences in proportions of E coli and Enterococcus spp between cats with and without biopsy-confirmed IBD. There were no significant differences in frequency of bacterial infection, type of infecting organism, or development of culture-based polymicrobial infections among comorbidities.

Clinical features in cats with and without bacterial cultures were similar, except for a significantly $(P<$ 0.001 each) greater proportion of cats with bacterial cultures having abdominal pain and hepatomegaly (Table 2). Among 135 cats with bacterial cultures, those with positive cultures had a significantly greater incidence of abdominal pain $(P=0.05)$ and lethargy $(P=0.009)$. There were no significant differences in clinical features between cats with gram-positive versus gram-negative isolates. Compared with cats with single bacterial isolates, a significantly greater proportion of cats with polymicrobial isolates had pyrexia $(P=0.05)$, abdominal pain $(P=0.001)$ and hepatomegaly $(P=0.05)$. Among clinicopathologic assessments, cats with positive cultures had a significantly $(P=0.01)$ higher median WBC count $(16.4$ $X 10^{3} / \mu \mathrm{L}$; range, $4.8 \times 10^{3}$ to $\left.48.1 \times 10^{3} / \mu \mathrm{L}\right)$, compared with cats with negative cultures (9.2 X 103/ $\mu \mathrm{L}$; range, $0.5 \times 10^{3}$ to $\left.49.2 \times 10^{3} / \mu \mathrm{L}\right)$. There were
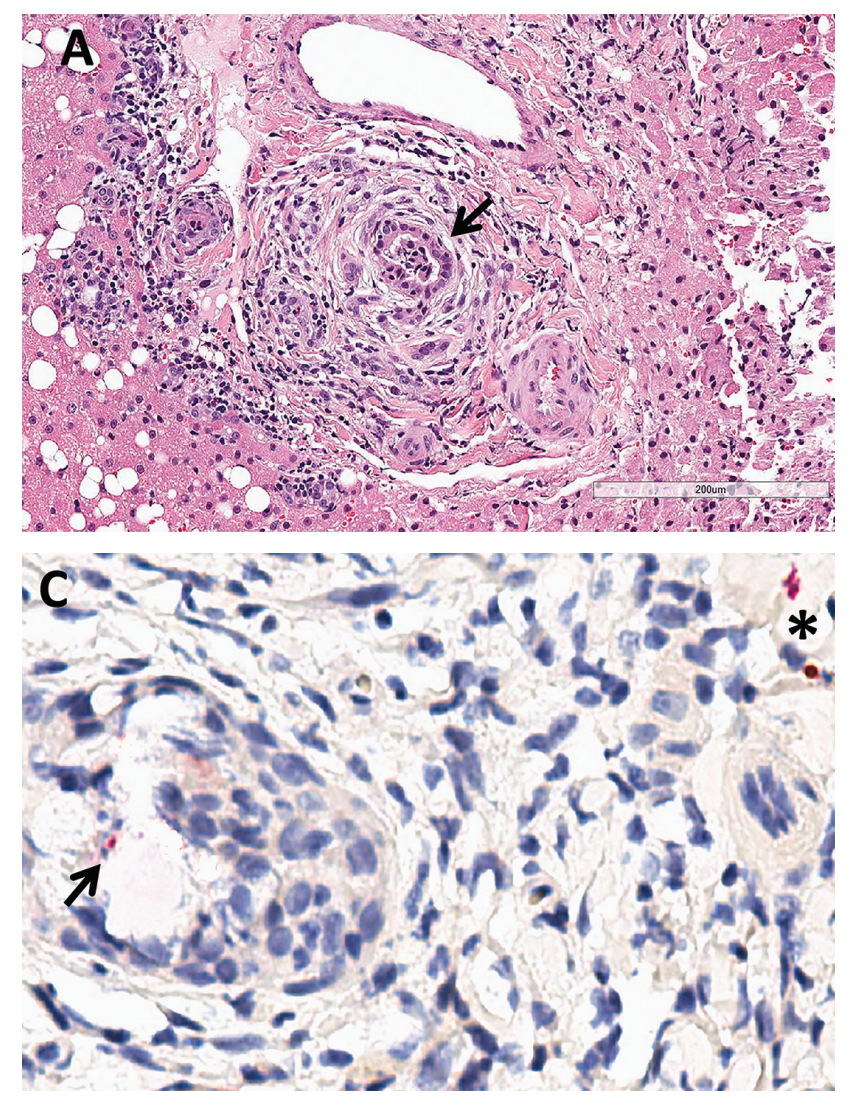

no significant differences between cats with and without positive bacterial cultures in fold-increase of serum total bilirubin concentration or liver enzyme activities, with the exception of alkaline phosphatase (ALP). Although the median fold-increase in ALP activity was modest in each group, ALP activity was significantly $(P<0.002)$ higher in cats with negative cultures than in cats with positive cultures (median fold increase, 2.4 vs 1.3). Significant differences also were observed in ALP activity between cats without versus with gram-positive isolates (median fold increase, 2.2 and 1.3 , respectively; $P=0.05$ ), cats without versus with gram-negative isolates (median fold increase, 2.3 and 1.2 , respectively; $P=0.009$ ), and cats without versus with polymicrobial isolates (median fold increase, 2.1 and 1.0 , respectively; $P=$ 0.007).

Regarding median age at presentation, duration of antecedent clinical illness, survival duration, and last recorded age, there were no significant differences between cats with positive versus negative bacterial cultures, cats with gram-positive versus gram-negative isolates, and cats with polymicrobial versus single isolate cultures (Table 3 and Supplementary Table S2).

\section{IHC detection of LTA and TLR-4}

None of the 20 control cats had positive LTA or TLR-4 IHC staining. Of 151 cats with S-CCHS that had IHC staining, 142 (94\%) were positive. When positive, IHC detection of LTA demonstrated single or multiple 

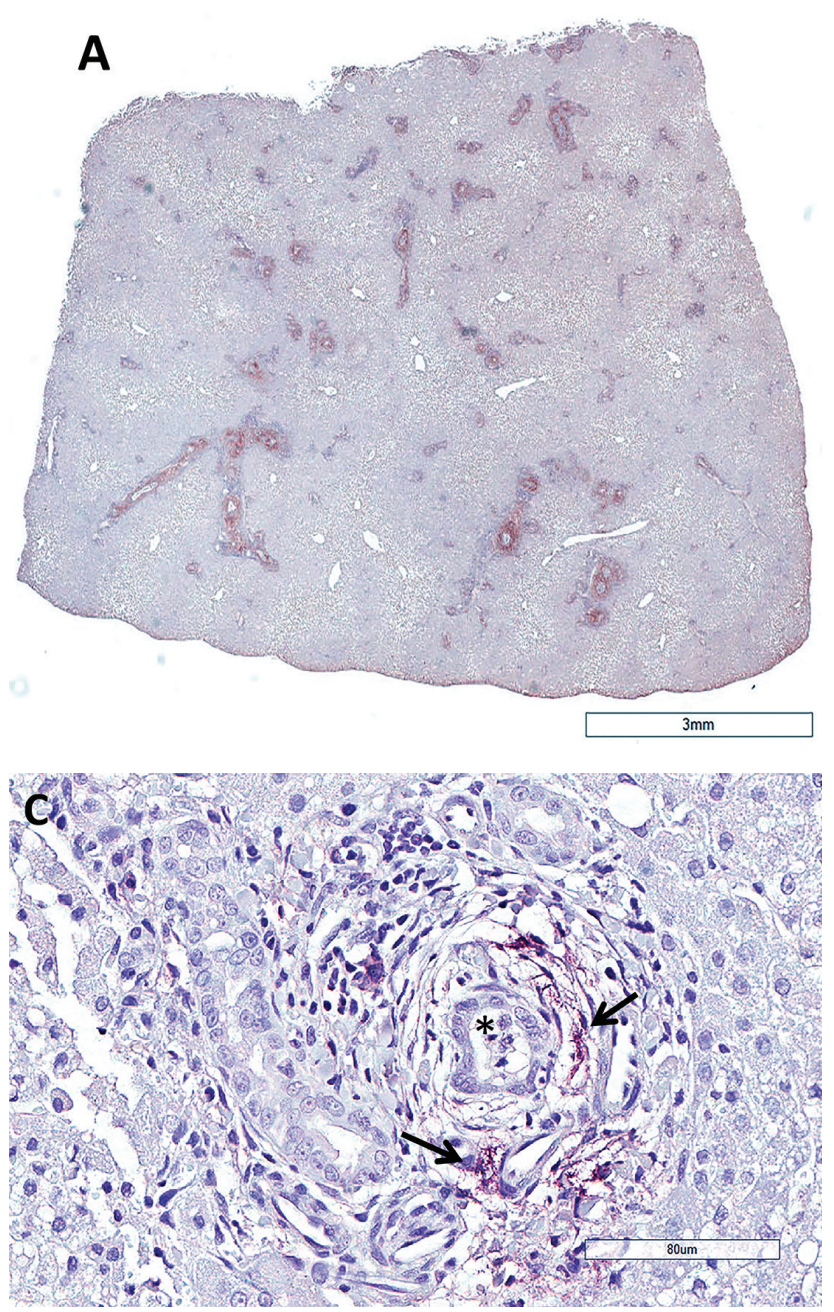

organisms within the lumen of bile ducts or phagocytes (ie, macrophages or neutrophils) adjacent to, but external to, bile ducts amid crowded inflammatory infiltrates (Figures 1 and 2). Strong positive LTA staining was especially notable in cats with periductal edema. However, positive staining within bile ducts as well as periportal or portal staining was often inconsistent within and among liver sections from a single cat. Positive LTA IHC staining also was detected within the gallbladder lumen adjacent to gallbladder epithelium, presumably within a mucosal bacterial biofilm (Figure 3). Occasionally, positive LTA IHC staining was seen within the crystalline structure or between laminating layers of choleliths. Immunohistochemical staining for TLR-4 expression demonstrated strong positive staining in neutrophils, macrophages, and biliary epithelium (bile ducts, gallbladder mucosa, and choledochal cyst epithelium) with only occasional staining of regional Kupffer cells and sinusoidal endothelium and rare weak multifocal staining of hepatocytes (Figures 4-7). Among 142 cats with positive IHC staining, 75\% were LTA positive and 70\% were TLR-4 positive. Among comorbidities, the prevalence of IHC-based bacterial detection ranged from $90 \%$ to $97 \%$, with LTA IHC positivity ranging from $72 \%$ to $80 \%$ and TLR-4 IHC positivity ranging from $68 \%$ to $83 \%$ of cats (Table 4 ). Dually positive

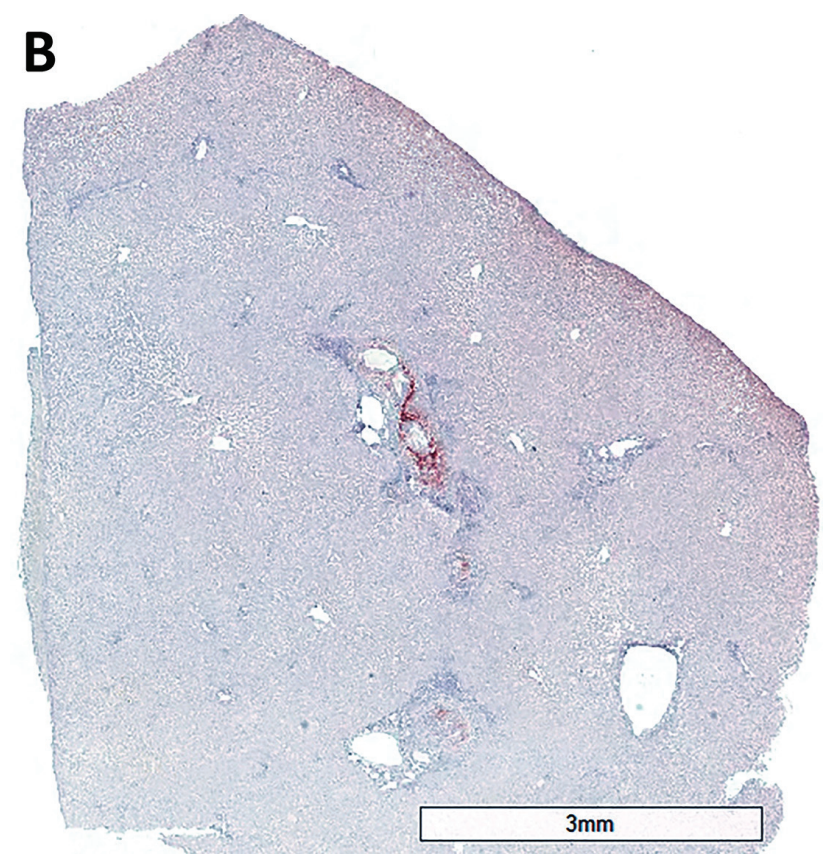

Figure 2-Photomicrographs of liver sections with IHC staining for LTA (red signal, hematoxylin counterstain) from 2 cats with S-CCHS. Each bar $=3 \mathrm{~mm}$. A-Corynebacterium spp were cultured from gallbladder bile and choleliths, whereas culture results for liver were negative. Positive staining for LTA (red staining) appears in most portal tracts confirming gram-positive bacteria. Gram stain of liver did not identify bacteria. B-Enterococcus spp were cultured from bile, whereas culture results for liver were negative. Note that only 2 larger portal tracts stain positively for LTA (implicating gram-positive bacteria). C-600X magnification of a liver section from the cat in panel A reveals intraluminal inflammatory debris in a centrally located bile duct (asterisk), periductal edema (white spaces), and small aggregates of bacteria (arrows) surrounded by or within macrophages. Gram staining of liver did not identify bacteria.

LTA and TLR-4 IHC staining (ie, IHC-based polymicrobial infection denoting presence of gram-positive and gram-negative bacteria) was observed in $45 \%$ of cats and was similar among comorbidities (42\% to 56\%).

Significantly $(P<0.001)$ more cats had evidence of infection by IHC staining (94\%) versus bacterial culture (69\%). The proportion of gram-positive versus gram-negative infections and polymicrobial infections determined by culture and IHC methods was not significantly different overall or among comorbidities. There also were no significant differences in frequency of IHC positivity, LTA or TLR-4 detection (ie, gram-positive vs gram-negative bacteria), or polymicrobial infection among comorbidities.

Clinical features were similar between cats with and without IHC assessments (except for a greater prevalence of lethargy in cats undergoing IHC staining; $P=0.008$ ), between cats with and without $\mathrm{IHC}$ positivity, and between cats with LTA or TLR-4 positivity (Table 2). Clinical features also were similar in cats designated as infected by culture or IHC methods, cats with gram-positive infection by culture or LTA IHC staining, cats with gram-negative infec- 

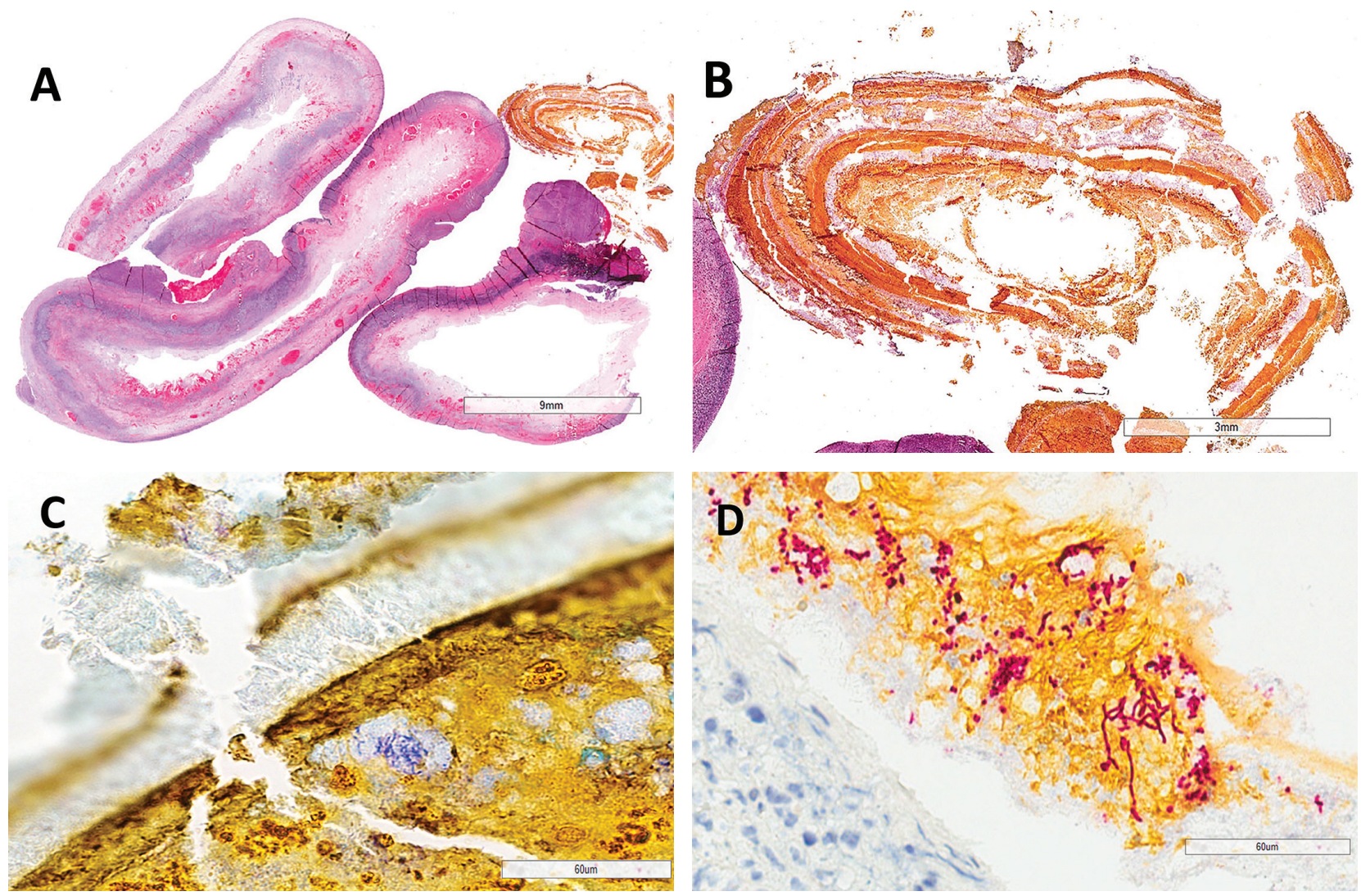

Figure 3-Photomicrographs of gallbladder and laminated cholelith (yellow-orange color) sections from cat with Escherichia coli and Enterococcus casseliflavus polymicrobial infection, as identified by bacterial culture of combined liver, bile, and crushed cholelith inoculate. A-Overview low magnification shows thick inflamed gallbladder wall, hemobilia, and laminated cholelith (top right). Bar $=9 \mathrm{~mm}$. B-Laminated cholelith. Bar $=3 \mathrm{~mm}$. C-Gram stain demonstrates mat of blue-staining grampositive bacteria within the cholelith matrix. Bar = $60 \mu \mathrm{m}$. D-Immunohistochemical staining for LTA (red signal, hematoxylin counterstain) illustrates chains, mats, doublets, and single gram-positive coccoid bacteria in gallbladder biofilm attached to the cholelith. Bar = $60 \mu \mathrm{m}$. Positive LTA IHC staining between lamination layers of the cholelith (not shown) was also evident.

tion by culture or TLR-4 IHC staining, and cats with polymicrobial infection by culture and IHC staining (Table 2). Among clinicopathologic tests, cats with positive LTA or TLR-4 IHC staining had a significantly $(P=0.05)$ higher median WBC count $\left(15.3 \times 10^{3} / \mu \mathrm{L}\right.$; range, $3.1 \times 10^{3}$ to $\left.71.7 \times 10^{3} / \mu \mathrm{L}\right)$ compared with $\mathrm{IHC}$ negative cats $\left(11.9 \times 10^{3} / \mu \mathrm{L}\right.$; range, $4.6 \times 10^{3}$ to 17.4 $\times 10^{3} / \mu \mathrm{L}$ ). However, there were no significant differences in the fold increase of serum total bilirubin concentration or liver enzyme activities between these groups, except for a significantly $(P=0.03)$ higher serum ALP activity in TLR-4-negative cats (median fold increase of 2.2) compared with that in TLR-4-positive cats (median fold increase of 1.3).

Regarding median age at presentation, duration of antecedent clinical illness, survival duration, and last recorded age (Table 3 and Supplementary Table S2), there were no significant differences between cats with positive versus negative $\mathrm{IHC}$ results, cats with LTA positivity versus TLR-4 positivity, and cats with single versus dual LTA and TLR-4 positivity (ie, IHC-designated polymicrobial infection) with the exception of younger age in the small number of cats with negative versus positive in-parallel testing. On inspection of the data, $9 \mathrm{IHC}$-negative cats had a younger median age at presentation, shorter median duration of antecedent illness, and longer median survival time, compared with 142 IHC-positive cats; however, these differences were not significant.

\section{Cats lacking bacterial cultures, cats surviving $\leq \mathbf{4 8}$ hours, cats with severe hypotension}

Cats without bacterial culture had a significantly $(P<0.001)$ shorter median survival time, compared with cats that had cultures performed (Table 3 ). This finding may have reflected a clinician's decision to forgo cultures in cats judged to have dismal prognoses (ie, cats with neoplasia, nonresponsive hypotension, or obtunded condition) and cats that died within 48 hours of presentation. Hypotension consistent with cholangiovenous reflux or reflecting comorbidities enhancing the risk for enteric bacterial translocation occurred in 19 cats. Among these cats, positive culture results were documented in 10 of 11 (91\%; 8 with gram-positive isolates, 7 with gramnegative isolates, and 5 with polymicrobial isolates). Immunohistochemical staining in 15 of 19 (79\%) hypotensive cats was positive in 14 of 15 (93\%), includ- 

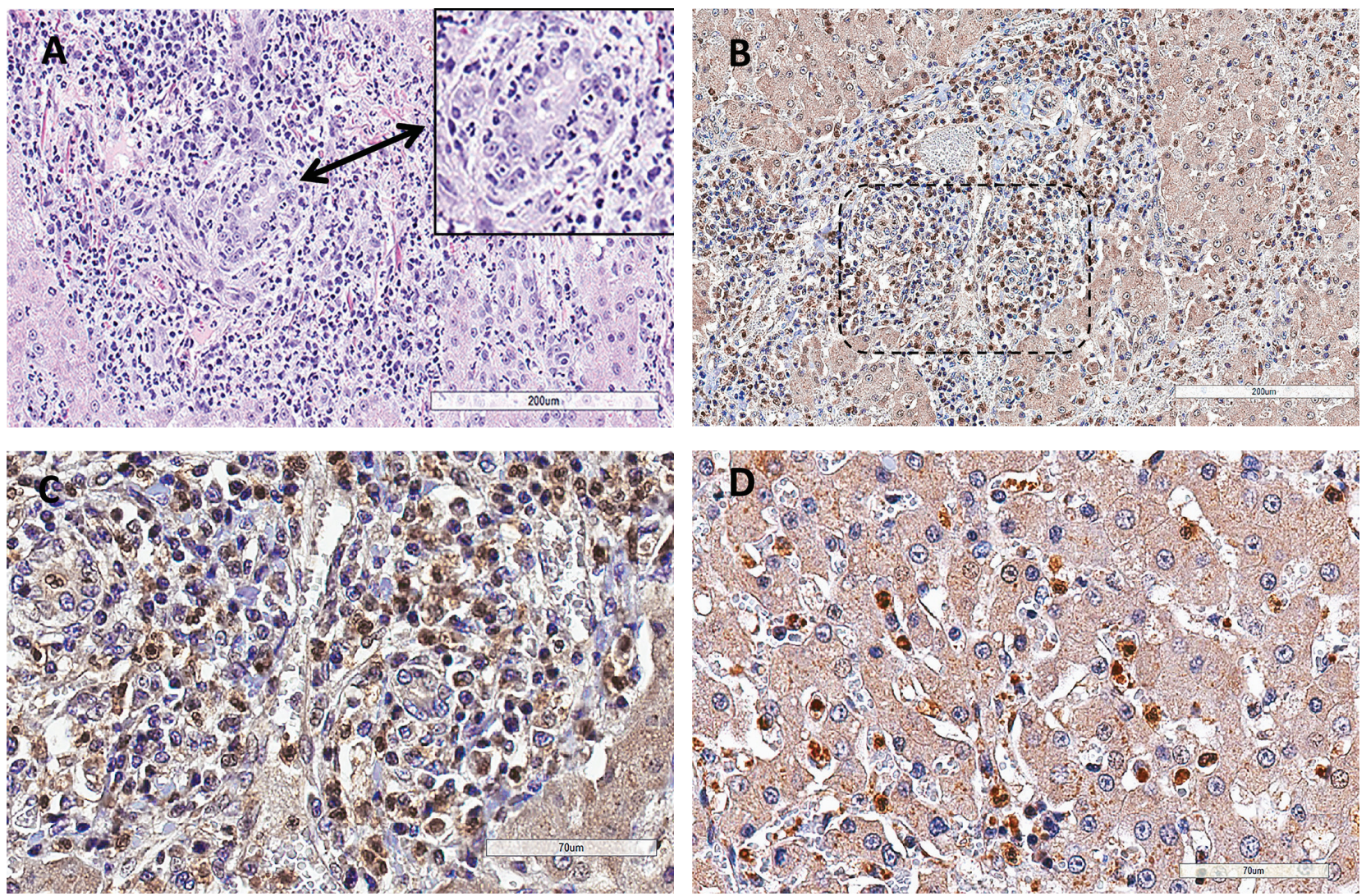

Figure 4-Photomicrographs of serial liver sections showing a single portal region from a cat with S-CCHS (A through C) and a midzonal parenchymal liver section from the same cat demonstrating neutrophilic sinusoidal flux (D). $E$ coli and a-hemolytic streptococci were cultured from liver. A-Liver section stained with H\&E showing too-numerous-tocount neutrophils and macrophages within portal and periportal regions, and neutrophils invading bile duct epithelium (inset). Bar $=200 \mu \mathrm{m}$. B-Serial sections of the same liver region as in panel A IHC stained for toll-like receptor-4 (TLR4) expression (brown signal, hematoxylin counterstain) showing numerous positive (brown-stained) neutrophils, macrophages, and occasional lymphocytes (implicating gram-negative bacteria endotoxin exposure beyond tolerogenic limits). Bar $=200 \mu \mathrm{m}$. C-Magnified (8X) image demarcated by dashed line in panel B highlights positive TLR-4 staining in inflammatory cells and occasionally ductal epithelium. Bar $=70 \mu \mathrm{m}$. D-Midzonal (zone 2) hepatic parenchyma demonstrating TLR-4 expression in neutrophils and monocytes fluxing across hepatic sinusoids. Bar $=70 \mu \mathrm{m}$.

ing 8 (57\%) with LTA positivity, 11 (79\%) with TLR-4 positivity, and $5(36 \%)$ with dual LTA and TLR-4 positivity (ie, IHC polymicrobial infection).

\section{Concordance of bacterial detection by culture and IHC}

Of 135 cats with bacterial cultures, 120 also had IHC staining. For gram-positive bacterial infection, concordant positive findings were documented in 61 cats (ie, gram-positive isolate[s] and positive LTA staining), and concordant negative findings were documented in 24 cats (ie, negative culture of grampositive bacteria and negative LTA staining). Thus, total concordance between methods for detection of gram-positive bacteria occurred in 85 (71\%) cats. Discordant findings included 30 cats with positive LTA staining without gram-positive culture isolates and 5 cats with gram-positive cultured isolates that were LTA negative. Among cats with discordantly positive LTA staining in the absence of gram-positive cultured isolates, the most plausible explanation was an inadequate or inappropriate tissue sample submission for culture. For example, 21 of 30 cats had only single liver $(n=16)$ or bile (5) inoculates cultured. In these cats, cultured bile often was only a small liquid bile aspirate placed on a sterile swab, and liver cultures in 10 cats were obtained by merely touching a sterile swab to a cut liver surface. In 3 LTA-positive but culture-negative cases, LTA staining detailed mats or chains of bacteria in gallbladder sections when only liver cultures had been submitted. In 12 cats with positive LTA staining and negative cultures for grampositive bacteria (4 with Caroli DPM), LTA only stained groups of bacteria adherent to epithelium of large bile ducts. Among 5 cats with cultured gram-positive isolates but negative LTA staining, 2 had combined liver and bile inoculates, 3 had single liver inoculates, and all cats only had LTA staining of a single liver section.

Regarding gram-negative bacterial infection, concordant positive findings were documented in 48 cats (gram-negative bacteria cultured and positive TLR-4 expression) with concordant negative findings in 41 cats (negative culture for gram-negative bacteria and negative TLR-4 staining). Thus, total concordance for gram-negative bacterial detection existed for 

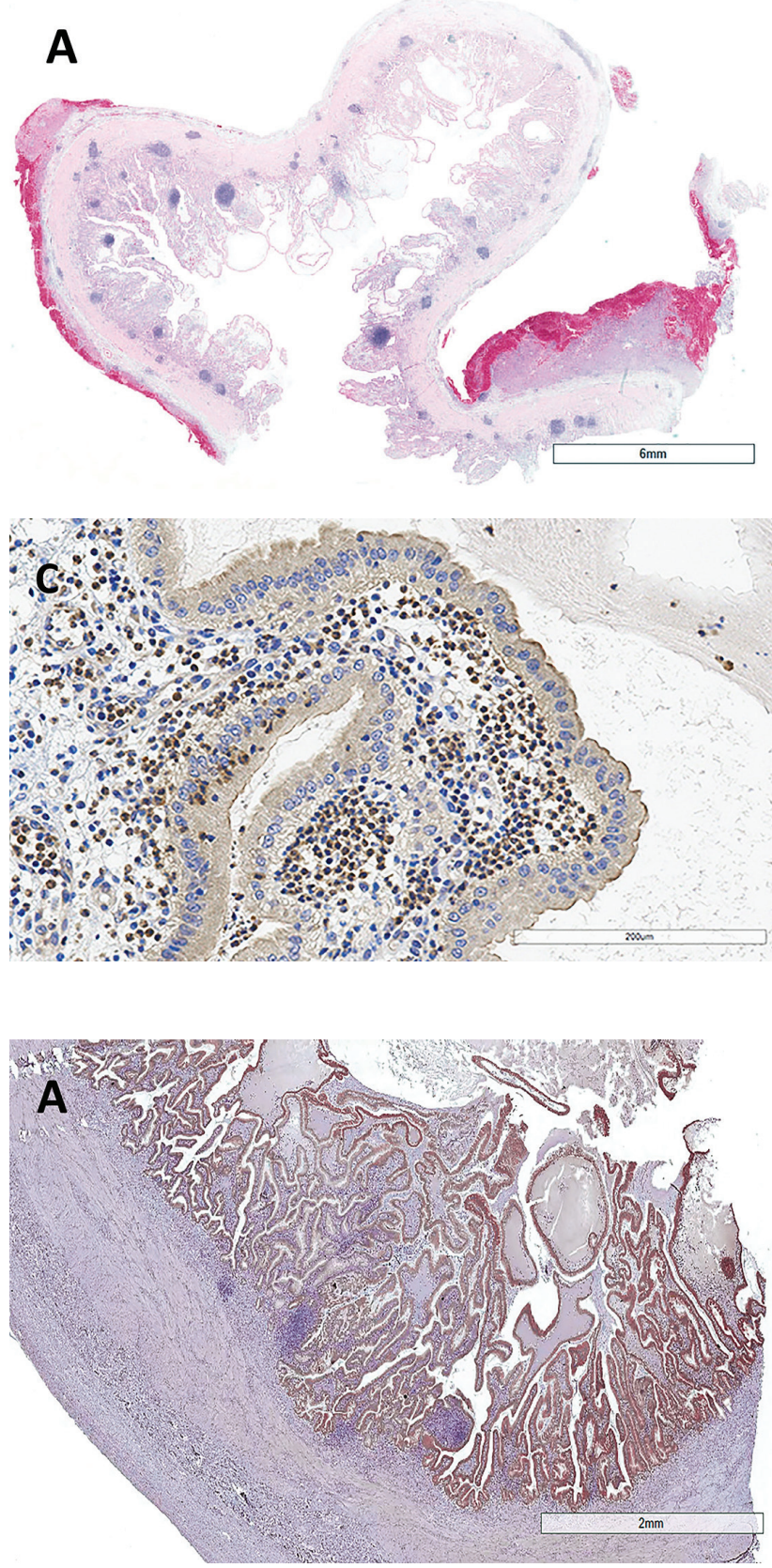

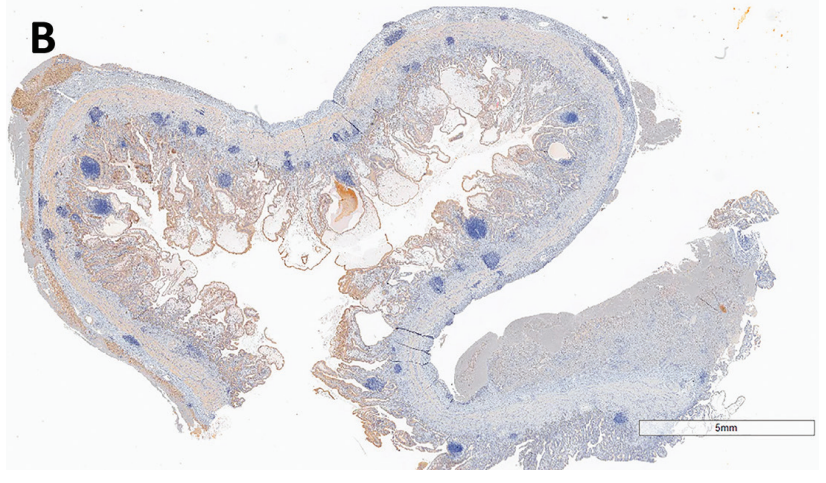

Figure 5-Photomicrographs of serial gallbladder sections from a cat with S-CCHS, cholecystitis, and cholelithiasis. Enterococcus spp and E coli were cultured from gallbladder bile, whereas bacterial culture of liver was negative. A-Gallbladder section stained with H\&E demonstrates proliferative mucosa and distinct blue-staining lymphoid follicles reflecting antigenic stimulation (infection). Bar $=6$ $\mathrm{mm}$. B-Serial section of tissue shown in panel A with IHC staining for TLR-4 expression (brown signal, hematoxylin counterstain) demonstrates diffusely positive staining of gallbladder epithelium and inflammatory cells. Bar = $6 \mathrm{~mm}$. C-Higher magnification of gallbladder wall from panel B illustrating TLR-4-expressing (brown staining) neutrophils infiltrating the proliferative gallbladder mucosa. Bar $=200 \mu \mathrm{m}$.

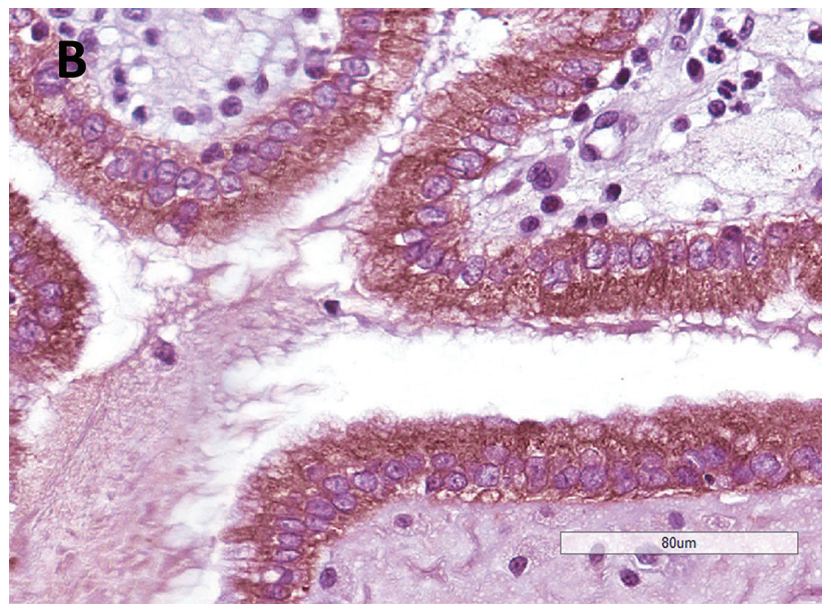

Figure 6-Photomicrographs of gallbladder sections from a cat with S-CCHS, cholelithiasis, and cholecystitis. Corynebacterium spp and E coli were cultured from gallbladder bile and crushed cholelith, whereas bacterial culture of liver was negative. A-Section of gallbladder with IHC staining for TLR-4 (brown signal, hematoxylin counterstain) demonstrates markedly thickened gallbladder wall and papilliferous mucosa (typically associated with feline cholelithiasis) with diffusely positive mucosal TLR-4 expression. Lymphoid follicles (blue circular lesions) reflect response to antigenic stimulation (infection). Bar $=2 \mathrm{~mm}$. B-Higher magnification of panel A highlights diffuse cytosolic TLR-4 expression (brown signal) within the gallbladder mucosa, reflecting pathologic exposure of luminal epithelial surface to gram-negative bacteria (endotoxin). Bar $=60 \mu \mathrm{m}$.

$89(74 \%)$ cats. Discordant findings included positive TLR-4 expression in 25 cats lacking cultured gramnegative bacteria and 6 cats with cultured gram-negative bacteria that were negative for TLR-4 expression. Among cats with discordant positive TLR-4 staining and negative cultures, the most plausible explanation was inadequate tissue sample submission. Among these cats, 18 had single liver $(n=12)$ or bile (6) cul- ture inoculates. Two cats with only liver samples cultured had positive TLR-4 expression in gallbladder sections with negative staining in liver. One cat with negative bile and liver bacterial cultures only had positive TLR-4 expression in gallbladder sections; 13 cats had positive TLR-4 expression in 1 or only a few large bile ducts that had dense periductular inflammation or that were plugged with intraluminal inflammatory 

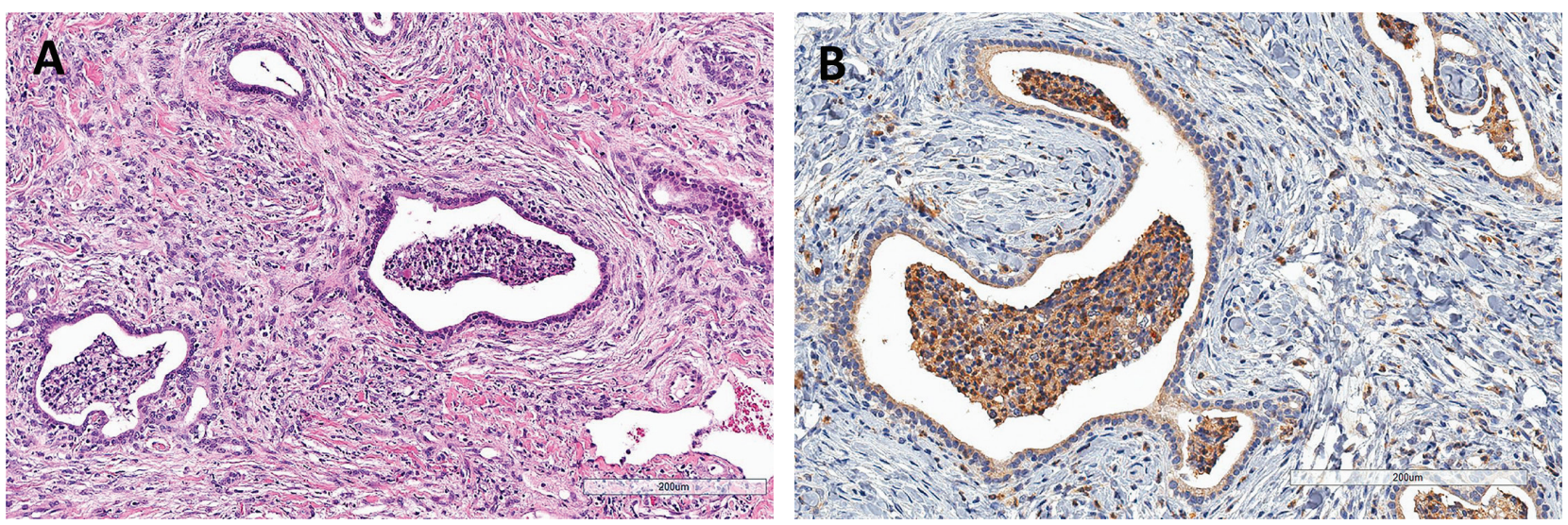

Figure 7-Photomicrographs of serial liver sections from a cat with Caroli ductal plate malformation (DPM) with severe S-CCHS associated with polymicrobial infection (Enterococcus spp and E coli). Bacteria were cultured from gallbladder bile and liver. A-H\&E-stained section of liver demonstrates malformed (irregular, corrugated, and dilated) bile duct profiles with dense purulent intraluminal debris. Bile ducts are embedded in exuberant extracellular matrix (fibrosis) typical of DPM congenital hepatic fibrosis. This cat had acquired portosystemic shunts evolved from presinusoidal portal hypertension caused by DPM. Bar = $200 \mu \mathrm{m}$. B-Immunohistochemical staining for TLR-4 (brown signal, hematoxylin counterstain) demonstrates diffusely positive TLR-4 expression in biliary epithelium and inflammatory infiltrates within and surrounding bile ducts. Bar $=200 \mu \mathrm{m}$.

Table 4-Results of IHC staining for lipoteichoic acid (LTA) and toll-like receptor 4 (TLR4) for cats with S-CCHS.

\begin{tabular}{lrrrc} 
Group & $\begin{array}{c}\text { IHC } \\
\text { positive }\end{array}$ & $\begin{array}{c}\text { LTA } \\
\text { positive }\end{array}$ & $\begin{array}{c}\text { TLR-4 } \\
\text { positive }\end{array}$ & $\begin{array}{c}\text { LTA + TLR-4 } \\
\text { positive* }\end{array}$ \\
\hline All cats with S-CCHS $(n=151)$ & $142(94)$ & $107(75)$ & $99(70)$ & $64(45)$ \\
EHBDO $(n=81)$ & $77(95)$ & $57(74)$ & $60(78)$ & $40(52)$ \\
Cholelithiasis $(n=65)$ & $61(94)$ & $49(80)$ & $44(72)$ & $32(53)$ \\
Cholecystitis $(n=61)$ & $57(93)$ & $44(77)$ & $45(79)$ & $32(56)$ \\
Cholecystectomy $(n=36)$ & $34(94)$ & $26(77)$ & $26(77)$ & $18(53)$ \\
Cholecystoenterostomy $(n=34)$ & $33(97)$ & $25(76)$ & $24(73)$ & $16(49)$ \\
DPM $(n=64)$ & $62(97)$ & $46(74)$ & $42(68)$ & $26(42)$ \\
Biopsy-confirmed IBD $(n=50)$ & $45(90)$ & $34(76)$ & $33(73)$ & $22(49)$ \\
Biopsy-confirmed pancreatitis $(n=37)$ & $36(97)$ & $26(72)$ & $30(83)$ & $20(56)$ \\
\hline
\end{tabular}

*Indicates a polymicrobial infection.

DPM = Ductal plate malformation.

See Tables 1 and 2 for remainder of key.
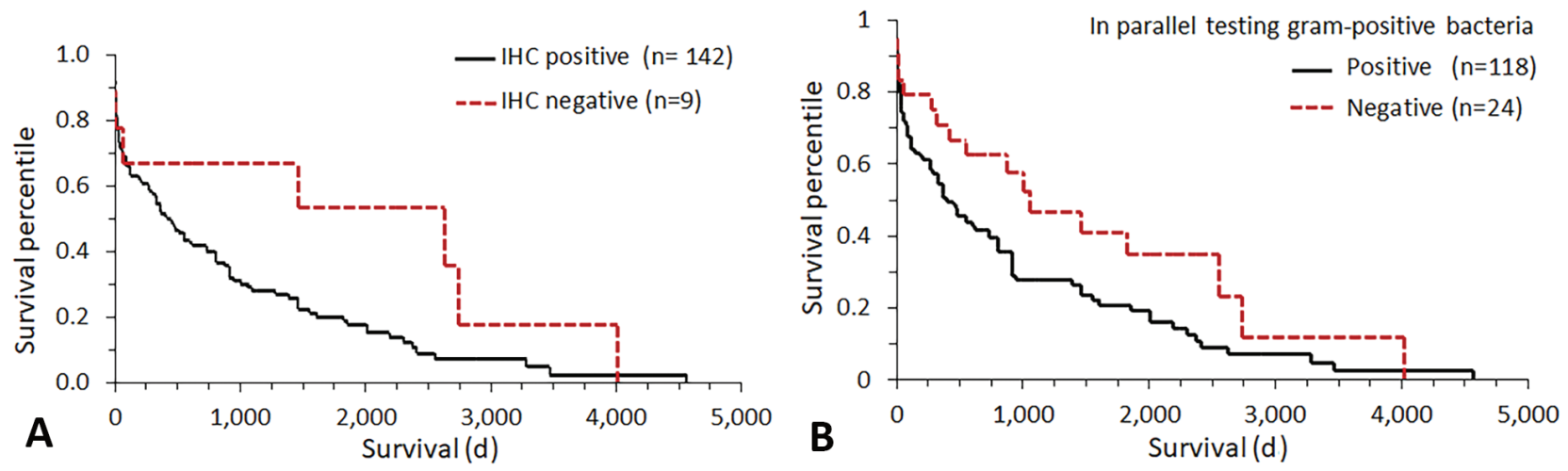

Figure 8-Kaplan-Meier survival curves illustrating shortened long-term survival in cats with bacterial infection based on IHC staining (A) and shortened long-term survival with gram-positive bacterial infection based on inparallel interpretation of culture and $\mathrm{IHC}$ results $(\mathrm{B})$.

debris. However, 6 cats with cultured gram-negative bacteria with negative TLR-4 expression had no plausible explanation for their discordance, other than a surmised variability in tissue or bile bacterial distribution and lack of gallbladder IHC staining.

\section{In-parallel interpretation of culture and IHC methods of bacterial detection}

Among 168 cats with S-CCHS, only 2 cats had neither bacterial culture nor IHC staining. Similar to independent detection of bacterial infection by cul- 
ture or IHC-based methods, there were no significant differences between frequency of bacterial infection, type of infecting organisms (ie, gram positive vs gram negative), or frequency of polymicrobial infections among comorbidities with in-parallel testing (Supplementary Table S3). Cats with in-parallel test polymicrobial infection $(n=79)$ had clinical signs similar to those without polymicrobial infection (Table 2), with the exception of significantly more cats with polymicrobial infection having abdominal pain $(P=0.05)$ and lethargy $(P=0.03)$.

With in-parallel testing, there were no significant differences in median age, duration of antecedent illness, or survival among categorical groups, with the exception that cats positive for bacterial infection were significantly $(P=0.02)$ older than cats that were negative (Table 3 and Supplementary Table S2).

\section{Survival time}

Kaplan-Meier survival analyses demonstrated shorter long-term survival (Gehan-Wilcoxon test, $P=$ 0.17 ; log-rank test, $P=0.02$ ) in cats with IHC-detected bacterial infection and shorter long-term survival (Gehan-Wilcoxon test; $P=0.07$; log-rank test, $P=$ 0.003 ) in cats with gram-positive bacterial infection with in-parallel testing (Figure 8).

\section{Discussion}

Results of this study confirmed a strong association between bacterial infection and S-CCHS in the largest population of affected cats studied to date. Culture and $\mathrm{IHC}$ methods detected bacterial infection in $69 \%$ and $94 \%$ of cats, respectively. It is clinically relevant that bacteria could be isolated from hepatobiliary inoculates despite common antecedent administration of broad-spectrum antimicrobials. Thus, the propriety of submitting samples for bacterial culture should not be dismissed based on prior antimicrobial administration. Bacterial cultures most commonly isolated aerobic or facultative anaerobic bacteria and confirmed polymicrobial infection in $44 \%$ of positive cultures. Similar to previous reports, $E$ coli and Enterococcus spp were common aerobic or facultative anaerobic isolates and Bacteroides spp and Clostridium spp were predominant fastidious anaerobic isolates. ${ }^{9,15,18,20,45-47}$ Interestingly, fastidious anaerobic bacteria were only isolated from polymicrobial infections-a circumstance that may have been influenced by the known ability of Bacteroides spp to facilitate polymicrobial populations. ${ }^{48,49}$ Because fastidious anaerobes require exacting environmental conditions and transport media, they can be difficult to isolate and may have been underestimated in this and former studies.49,50 The approximately $22 \%$ isolation frequency of fastidious anaerobes among isolated bacteria shown herein justifies submission of samples for anaerobic cultures. Further, our findings caution that isolation of only fastidious anaerobic bacteria, particularly Bacteroides spp, should heighten concern for polymicrobial infections. ${ }^{15,18,20,45-50}$ Composition of cultured polymicrobial isolates varied widely, including $\geq 2$ gram-positive isolates, $\geq 2$ gram-negative isolates, or both gram-positive and gram-negative isolates. No- tably, 1 cat with chronic extracorporeal bile drainage had 7 different pathogens isolated. Among comorbidities, there were no significant differences in frequency of culture positivity, isolation of gram-positive versus gram-negative bacteria, isolation of aerobic or facultative anaerobic bacteria versus fastidious anaerobic bacteria, or polymicrobial infection. The spectrum of bacterial isolates in this study implicated an enteric source, most likely acquired from bacterial translocation or retrograde ascension across the sphincter of Oddi. Pioneering investigations of enteric bacterial translocation (rodent studies) demonstrate a more rapid flux of E coli and other indigenous aerobic or facultative anaerobic bacteria, compared with fastidious anaerobes. ${ }^{51}$ These observations coordinate with bacterial isolates identified in this and former feline studies.

Previous investigations of the diagnostic utility of bile collected by cholecystocentesis for detection of hepatobiliary infection report positive cultures in 14\% to $36 \%$ of cats. ${ }^{20,45,47}$ In those studies, cultures were used in a screening capacity to detect hepatobiliary infection or disease as opposed to our use of culture as a diagnostic metric in cats with confirmed S-CCHS. One study of bile samples collected by cholecystocentesis from cats with suspected hepatobiliary disease reported a lower prevalence of positive cultures $(25 / 72[35 \%])$ than found in the present study. This may reflect the superiority of using combined inoculates for bacterial culture supported by our findings or that the former study may have sampled cats lacking hepatobiliary disease. Also in the former study, $75 \%$ of 65 positive bile cultures ( 40 dogs and 25 cats) involved single bacterial isolates. ${ }^{47}$ This finding contrasts with the present study, where a larger percentage of isolates were polymicrobial (44\%). Yield of bacterial isolates from bile compared with liver has been addressed in 2 additional studies ${ }^{20,45}$ of cats with suspected hepatobiliary disease. One study 45 showed equivalent culture positivity from liver (1/7 [14\%]) and bile (11/80 [14\%]). The other study 20 proclaimed bile a superior culture inoculate based on relatively sparse data (positive cultures in 7/49 [14\%] liver and $5 / 14$ [36\%] bile inoculates). In the latter study, 83\% of positive cultures (jointly reported for dogs and cats) yielded single isolates. ${ }^{20}$ Frequency of bacterial isolation from different culture inoculates reported $E$ coli isolation from $33 \%$ of liver, $40 \%$ of bile, and $60 \%$ of combined liver and bile samples and reported Enterococcus isolation from $63 \%$ of bile and $67 \%$ of combined liver and bile samples. ${ }^{20}$ The present study documented a higher frequency of positive cultures and polymicrobial infections, likely reflecting advantage gained through combined inoculate cultures in a population of cats with confirmed S-CCHS. For combined inoculates, we selectively included biliary debris, centrifuged bile sediment, gallbladder mucosal scrapings, and crushed choleliths considering that these sources would more likely harvest relevant bacterial biofilms.

Immunohistochemical staining suggested bacterial involvement in 94\% of cats with S-CCHS, a significantly higher frequency than detected using bacterial culture in this and former feline studies. ${ }^{20,45,47}$ We also recognized superior performance of $\mathrm{IHC}$ staining over 
Gram staining for detection of bacteria in histologic sections. ${ }^{52}$ We found no predominance of gram-positive versus gram-negative bacterial infection by either culture or $\mathrm{IHC}$ methods and documented a similar frequency of polymicrobial infection using these methods (despite the declared limitation that IHC staining cannot detect multiple species with similar Gram staining characteristics). To optimize bacterial detection, we leveraged in-parallel interpretation of culture-based and IHC-based test results applying a criterion that either positive culture or IHC staining (LTA or TLR-4) would declare a cat infected. ${ }^{44}$ This in-parallel testing strategy was adopted to minimize false negative findings, important for investigating the relationship between bacterial infection and S-CCHS. In-parallel testing revealed a $93 \%$ frequency of bacterial infection in cats with $\mathrm{S}-\mathrm{CCHS}$. We found no predilection for bacterial infection, gram-positive versus gram-negative infection, or polymicrobial infection among comorbidities with culture-based, IHC-based, or in-parallel testing.

We demonstrated $71 \%$ and $74 \%$ concordance between culture-based and IHC-based detection of gram-positive and gram-negative bacteria, respectively. Finding some discordance was not surprising in light of findings reported previously in small studies ${ }^{19-22,45}$ of cats that investigated concordance in results between liver and bile bacterial culture, culture and PCR-detected bacterial genome, and culture and bacterial detection by fluorescent in situ hybridization. It is not unreasonable to conclude that discordance between culture and IHC methods shown in the present study reflected uneven distribution of bacteria in liver, bile, bile ducts, gallbladder, malformative ductal structures. or choleliths and insufficient or nonrepresentative sampling of relevant tissues.

In health, the duodenal papilla functions as a protective barrier between the biliary tree and alimentary canal, thwarting retrograde colonization by enteric bacteria. ${ }^{53,54}$ Although bile is generally considered sterile in healthy cats, transient bacterobilia has been experimentally documented in cats through accrual of bacterial biofilm on sterilely implanted gallbladder foreign bodies. ${ }^{55}$ Transient bacterobilia heightens the risk for hepatobiliary infection especially in conjunction with predisposing factors including 1 ) bile flow stasis permissive to bacterial replication and biofilm accumulation, and increased intrabiliary pressure disseminating bacteria (ie, any cause of EHBDO, Caroli DPM, or choledochal cyst DPM); 2) irregular surfaces conducive to bacterial implantation and development of sessile biofilms (ie, biliary mucosal irregularities such as gallbladder mucosal proliferation associated with cholelithiasis, Caroli DPM, and biliary neoplasia); and 3) cholelithiasis functioning as a bacterial biofilm reservoir and provocateur of intermittent bile duct obstruction. Episodic dispersal of planktonic bacteria from sessile biofilm niches in the biliary tree (gallbladder or Caroli DPM sacculated bile ducts or choledochal cysts), or any source of fluxing bacterobilia, poses a risk for bacterial dissemination to other portions of the biliary and pancreatic ductal systems. Conditions provoking these risks are inarguably linked with the comorbidities identified in this study.
It is widely acknowledged that complete or intermittent bile duct obstruction increases the risk for bacterobilia, an association also experimentally documented in cats. ${ }^{56-70}$ In the present study, EHBDO was the most common comorbidity. Mechanical bile duct obstruction increases vulnerability to bacterial infection through several mechanisms. ${ }^{56,58-70}$ First, increased biliary pressure damages structural integrity of tight junctions between hepatocytes, increasing paracellular entry of portal-circulated bacteria into hepatocytes and subsequently into canalicular bile. ${ }^{58-60}$ Second, impaired Kupffer cell surveillance (ie, reduced bacterial phagocytosis) escalates hepatic bacterial and endotoxin exposure and their sinusoidal dissemination. ${ }^{61,62}$ Third, disrupted enterohepatic bile acid flux permits enteric dysbiosis and bacterial translocation. ${ }^{63-65}$ Fourth, reduced enteric flux of biliary IgA, with concurrent bacterial dysbiosis, facilitates enteric translocation. ${ }^{66-68}$ Fifth, because bile salts can deactivate enteric endotoxin, reduced enterohepatic bile acid flux in EHBDO increases hepatic endotoxin exposure that may escalate tissue inflammation and injury.69,70 These factors collectively heighten risk for cholangiovenous reflux, the phenomenon provoking acute dissemination of endotoxin and bacteria into the systemic circulation leading to severe nonresponsive hypotension.11,38,71-73 Cholangiovenous reflux is most often recognized in cats undergoing biliary surgery and was suspected in a subset of cats in the present study. ${ }^{11}$

As in humans, the normal anatomic anastomosis between biliary and pancreatic ductal systems in cats permits cross-system contamination. ${ }^{74}$ In humans, intermittent or incomplete mechanical obstruction at the duodenal papilla increases the risk for ascending infection. ${ }^{54}$ Indeed, we confirmed a similar scenario in cats with transiting microcholelithic debris that impaired patency or competency of the duodenal papilla. ${ }^{1}$ Transient recurrent lethargy, reclusiveness, inappetence, mild jaundice, fluctuating liver enzymes, biochemical markers implicating pancreatic inflammation, and hyperbilirubinemia often manifested for weeks to months before cholelithiasis was ultimately recognized as the causal factor in many of these cats. In some cats, microcholeliths limiting patency of the duodenal papilla were only recognized upon surgical flushing of the common bile duct. ${ }^{1}$ We posit that a clinical syndrome mimicking "idiopathic pancreatitis" evolves from cholelith-induced duodenal papilla incompetence or occlusion in cats and that this condition increases the risk for ascension of enteric bacteria into the biliary system. ${ }^{1}$ Although we suspected this syndrome in $>50$ cats of the present study, we were only able to ultrasonographically or surgically confirm causal choleliths in a subset. Our findings are similar to the well-documented association between microcholelithiasis, hepatobiliary infection, and pancreatitis in humans. . $^{175-79}$ We infer from these observations that feline "idiopathic pancreatitis" has an important association with S-CCHS and cholelithiasis. ${ }^{1}$

Cholelithiasis is often associated with bacterobilia in humans. ${ }^{80-82}$ The spectrum of bacterial isolates from humans with cholelithiasis is strikingly similar to those described herein. Among cats with cholelithiasis in the 
present study, 92\% had bacterial infection based on inparallel testing (ie, $80 \%$ gram positive, $79 \%$ gram negative, and $60 \%$ polymicrobial). In our companion report, ${ }^{1}$ we document longstanding remission and improved survival with cholelith removal and cholecystectomy in cats with S-CCHS. Importantly, infection and cholelithiasis may recur if the gallbladder is salvaged rather than removed. Whether bacterial infection initiates cholelithiasis or cholelithiasis initiates bacterial infection cannot be determined from the present study and remains a contentious issue in human medicine.

Concurrent IBD and other conditions conducive to enteric bacterial translocation or incontinence of the sphincter of Oddi (ie, regional duodenitis, complications of pancreatitis, or enteric lymphoma) explain similarities between cultured bacteria and enteric flora. $8,32,35,54,56,83$ Enteric bacterial translocation in IBD is multifactorial, reflecting altered structural integrity (eg, microvilli, tight junctions, and change in vascular and lymphatic permeability) as well as enteric dysbiosis. ${ }^{32,53,56,58,83}$ As expected, the majority of cats undergoing enteric biopsy in the present study had concurrent IBD. Similarly, as expected, we confirmed bacterial infection in the majority of cats with DPM. Once bacterobilia becomes established in DPM, chronic residence in cystic and irregular biliary structures follows. In cats with a choledochal cyst DPM phenotype, distortion or obstruction of the duodenal papilla leading to EHBDO appeared to provoke bacterial infection. ${ }^{1}$

As the liver receives approximately $70 \%$ of its perfusion from the portal circulation, it continually interfaces with gut-derived bacteria, bacterial components, environmental toxins, and food-associated antigens. Portal circulation of bacteria is considered the most common source of gallbladder inoculation. Once the hepatobiliary system is inoculated, development of a bacterial biofilm can sustain bile bacterial contamination. Protective responses thwarting systemic bacterial invasion are essential in the liver and are orchestrated by resident immune cells (Kupffer cells, Iymphocytes, natural killer cells, dendritic cells, and B cells), nonparenchymal cells (endothelial cells and stellate [or Ito] cells), biliary epithelium (cholangiocytes), hepatocytes, and systemically derived WBCs fluxing across sinusoids (neutrophils, monocytes, and lymphocytes). ${ }^{80,84-87}$ These defenses normally orchestrate initial responses against invading bacteria and endotoxin and play a role in mitigating innocent bystander selfinflicted injury. The upshot is that bile is episodically exposed to bacteria and bacterial products or motifs, including LPS, LTA, and bacterial DNA fragments, collectively designated pathogen-associated molecular patterns (PAMPs). Numerous studies $31-34,84,86-89$ confirm an enhanced pathologic PAMP milieu in the liver of humans and animals with hepatobiliary disease and IBD. Homeostasis among a complex system of defense responses is essential to avoid persistent tissue injury.

Toll-like receptors are PAMP-recognition receptors important for innate and adaptive immunity. $32,33,86,88$ For TLR-4 expression, upregulation occurs upon pathologic exposure to gram-negative bacterial membranes. The TLR-4 expression initiates signaling pathways that form and release inflammatory cytokines and type I interferon. ${ }^{88}$ Hepatocytes express
mRNA for all TLRs, although only TLR-2 and TLR-4 have functional activity toward LPS clearance. ${ }^{87,89-93}$ Cholangiocytes, sinusoidal endothelium, Kupffer cells, and sinusoidal WBCs also express TLR-4 in response to pathologic LPS exposure. ${ }^{89-93}$ Interpretation of TLR-4 expression in liver is complicated by its perfusion with portal circulation laden with PAMPs as well as its essential function as the major site for LPS clearance. ${ }^{93,94}$ Although expression of TLR-4 in Kupffer cells potentiates clearance of LPS and portaldisseminated gram-negative bacteria, unregulated TLR-4 expression in response to "normal" PAMP exposure could be deleterious (eg, stimulating release of injurious TNF- $a$ and formation of reactive oxygen intermediates). ${ }^{94-96}$ Consequently, it is crucial that this response be tempered in health, through a process called tolerization. ${ }^{94-96}$ This process dampens responsiveness of hepatocytes, sinusoidal endothelium, and Kupffer cells to LPS, mitigating TLR-4 expression in the face of "normal" endotoxin exposure. ${ }^{94,96}$ Heightened LPS exposure, similar to that suspected in cats with S-CCHS, is documented in humans and experimental animals with cholangiopathies, EHBDO, and endotoxemia. ${ }^{84,87,97-103}$ Tolerization of Kupffer cells, sinusoidal endothelial cells, and hepatocytes reconciles with findings discovered in the present study. ${ }^{84,87,97-103}$ We document strongest TLR-4 expression in portal inflammatory cells and biliary epithelium, with only occasional staining of zone 1 and zone 2 Kupffer cells, hepatocytes, and sinusoidal endothelium. Although positive TLR-4 staining in this study might reflect normal enterohepatic flux of endotoxin and bacteria, absence of positive TLR-4 staining in 20 control cats strongly argues against this possibility. We thus conclude that findings in this study document pathologic endotoxin exposure, implicating gram-negative bacterial infection and endotoxemia in a substantial number of cats with S-CCHS. We demonstrate strongest IHC staining proximate to duct-centric inflammation, within inflamed gallbladder sections (epithelium and inflammatory infiltrates), and mural sections from infected choledochal cysts, as compared with hepatocytes, sinusoidal endothelium, or Kupffer cells. ${ }^{87}$ Compellingly, sites with the strongest IHC staining for TLR-4 were the same locations from which inoculates were more likely to yield positive bacterial cultures.

Interpretation of LTA was less complicated than TLR-4 expression because staining directly incriminates presence of gram-positive bacterial cell wall components. We identified mats, chains, and small clusters of bacteria, and in a few cases with periductal edema, a diffuse periductal staining pattern (Figures 1-3). Our findings clearly demonstrated patchy distribution of bacteria within tissue sections, explaining discordant negative cultures in some cases.

A critical, clinically relevant finding in the study reported here is the value of consolidating aseptically collected tissue (liver, gallbladder wall, and choledochal cyst fluid and structure), bile (especially particulate debris, centrifuged sediment, or bile scraped from the gallbladder mucosa), and crushed choleliths into a combined inoculate for bacterial culture. This maneuver appeared to optimize culture detection of relevant pathogens while minimizing cost. In this large feline 
data set, we confirmed significantly higher culture positivity with combined inoculates (82\%) than with single inoculates (48\%). Furthermore, our culture strategy achieved higher culture positivity than previously reported for single, and even for combined, liver and bile inoculates from cats. ${ }^{20,21,45-47}$ This is not surprising considering that we microscopically demonstrated uneven bacterial distribution among sampled tissues (Figure 2) with IHC staining. We also documented instances with LTA staining where bacteria were solely identified nestled against gallbladder mucosa or within intrahepatic ductal structures, duct plugging debris, periductal macrophages, crystalline structure or laminating layers of choleliths, and fluid collected from choledochal cysts, despite negative cultures from single bile or liver inoculates in those same patients.

Recently, cholecystocentesis for routine surveillance of hepatobiliary infection has been popularized. $45-47,104$ However, findings in the present study query the reliability of negative culture results for cholecystocentesed bile. In cholecystocentesis, bacteria are best retrieved from bile only with near complete emptying of the gallbladder ( 3 to $5 \mathrm{~mL}$ in cats). Based on our microscopic and IHC findings, bacteria were entangled in gravitationally dependent biofilm nestled against gallbladder mucosa or within microcholelithic debris. It is this microbial biofilm that likely sustains persistent bile-borne infection. ${ }^{105-108}$ Patient positioning in dorsal recumbency for ultrasound-guided cholecystocentesis puts such biliary sediment at the furthest distance from the needle puncture site.

As expected, we confirmed a significantly shorter long-term survival in cats with versus without bacterial infection. We also confirmed a significantly shorter survival time in cats with gram-positive infections. Although we demonstrated a pathologic response to endotoxemia in many cats by IHC detection of TLR-4 expression, we did not discover a significant survival impact associated with gram-negative bacterial infection. There was a higher prevalence of pyrexia, abdominal pain, and lethargy in cats with positive culture results than in cats with negative results and a higher prevalence of abdominal pain and hepatomegaly in cats with polymicrobial infections than in cats with single bacterial isolates. However, the clinical utility of these observations is limited. Pyrexia, abdominal pain, and lethargy are common features in a multitude of feline illnesses and cannot function as reliable differentiating metrics for predicting S-CCHS or polymicrobial infection. Likewise, marginal but significant differences in WBC count in cats with versus without bacterial infection and a higher fold increase in serum ALP activity in cats without versus with bacterial infection lack diagnostic clinical utility.

Findings of the present study support early initiation of broad-spectrum antimicrobials as soon as $\mathrm{S}-\mathrm{CCHS}$ is reasonably suspected in cats. This means that, in most cases, empirical selection of antimicrobials will be advisable before specific pathogens are identified. Wisdom regarding antimicrobial selection for cats with $\mathrm{S}-\mathrm{CCHS}$ can be gained from 2 studies, one investigating bacterial isolates from feline and canine bile or liver ${ }^{20}$ and another involving bile collected from humans with acute cholangitis and cholelithiasis. ${ }^{81}$ Although responsible stewardship of antimicrobial use should be strategized based on pathogen targeting, the cited human study ${ }^{81}$ documented positive response to combined use of antimicrobials. We conclude that antimicrobial therapy should be the cornerstone of case management in feline $\mathrm{S}-\mathrm{CCHS}$, along with appropriate surgical interventions (ie, cholecystectomy, cholelith removal, biliary tree decompression in EHBDO, or cholecystoenterostomy). A trimodal antimicrobial protocol commonly used for cats in this study included 1) a fluoroquinolone; 2) ampicillinsulbactam, amoxicillin clavulanate, or imipenem (IV in critically ill cats); and 3) metronidazole (dose reduced by $50 \%$ in cats with hepatobiliary jaundice). The high frequency of TLR-4 expression in cats of the present study confirmed the long-conjectured risk for endotoxemia as a complicating factor in cats with obstructive cholangiopathies, biliary sepsis, and S-CCHS. Our findings also implicated endotoxemia as a contributing factor in cats developing poorly responsive hypotension.

After S-adenosylmethionine (SAMe) was introduced to veterinary medicine in 2005 , administration of bioavailable SAMe $(20 \mathrm{mg} / \mathrm{kg}$, PO, once daily on an empty stomach) was recommended for most cats in the study reported here. This recommendation aligns with the ability of this substrate to replenish hepatic glutathione consumed by oxidative injury in necroinflammatory liver disorders. ${ }^{109,110}$ Experimental work using an endotoxemic mouse model also demonstrates that SAMe can interrupt TLR-4 signaling in Kupffer cells and sinusoidal endothelium, simultaneously inhibiting TNF-a elaboration. 111 We also recommend administration of ursodeoxycholic acid (10 to $15 \mathrm{mg} / \mathrm{kg}$, PO, divided twice daily given with food for best bioavailability) to cats with S-CCHS associated with nonobstructive cholangiopathies, further discussed in our companion report. ${ }^{1}$ Caution is warranted, however, to avoid administration of ursodeoxycholic acid in EHBDO before biliary decompression, as this may escalate associated liver injury and fibrosis. 112,113

The spectrum of bacterial isolates from cats with S-CCHS included a substantial number with Enterococcus isolates. These opportunistic pathogens are inherently resistant to many commonly used antimicrobials (eg, cephalosporins or penicillins) and transfer genes conferring antimicrobial resistance and virulence factors to other organisms. ${ }^{114,115}$ Popularized use of probiotics for enteric bacterial biome modification in IBD has raised concern about products containing Enterococcus spp. Mechanistically, probiotics are proposed to alter host enteric flora, modulate enteric immunity, and improve intestinal barrier functions. ${ }^{114-117}$ Although enterococci are widely used in food production, their increasing prevalence as opportunistic pathogens has raised questions about their suitability in probiotics. ${ }^{114,118}$ Standards assuring lack of pathogenicity of enterococci in probiotic supplements have been hard to meet, including the absence of known virulence genes and a hampered ability to exchange DNA conferring antimicrobial resistance. ${ }^{114,115}$ At present, there are no medically approved probiotics for human consumption in Europe or the US containing enterococci. ${ }^{114,115}$ Consequently, it may be wise to avoid such probiotics in cats with S-CCHS.

In conclusion, the present study confirmed a strong association between feline S-CCHS, bacterial in- 
fection, and pathologic endotoxin exposure and advises appropriate therapeutic considerations. Contrasting bacterial culture and IHC findings suggested an uneven distribution of bacterial pathogens in hepatobiliary tissues and bile, stressing the importance of combining tissue and bile inoculates for bacterial culture. We are not advocating routine use of the described IHC stains for clinical diagnostic purposes. Stain utility requires in-laboratory IHC validation in feline tissues, concurrent staining of positive and negative feline control samples, and individual training in stain interpretation.

\section{Acknowledgments}

Funded in part by the Winn Foundation and Cornell Feline Health Center.

The authors declare that there were no conflicts of interest.

\section{References}

1. Center SA, Randolph JF, Warner KL, et al. Clinical features, concurrent disorders, and survival time in cats with suppurative cholangitis-cholangiohepatitis syndrome. J Am Vet Med Assoc. 2022;260:212-227.

2. Naus MJ, Jones BR. Cholelithiasis and choledocholithiasis in a cat. N Z Vet J. 1978;26(6):160-161.

3. Hirsch VM, Doige CE. Suppurative cholangitis in cats. J Am Vet Med Assoc. 1983;182(11):1223-1226.

4. Wolf AM. Obstructive jaundice in a cat resulting from choledocholithiasis. J Am Vet Med Assoc. 1984;185(1):85-87.

5. Morrison WB. Cholangitis, choledocholithiasis, and icterus in a cat. Vet Pathol. 1985;22(3):285-286.

6. Jorgensen LS, Pentlarge VW, Flanders JA, Harvey HJ. Recurrent cholelithiasis in a cat. Compend Contin Educ Pract Vet. 1987:9:265-270.

7. Jackson MW, Panciera DL, Hartman F. Administration of vancomycin for treatment of ascending bacterial cholangiohepatitis in a cat. J Am Vet Med Assoc. 1994;204(4):602-605.

8. Gagne JM, Armstrong PJ, Weiss DJ, Lund EM, Feeney DA, King VL. Clinical features of inflammatory liver disease in cats: 41 cases (1983-1993). J Am Vet Med Assoc. 1999;214(4):513-516.

9. Lapointe JM, Higgins R, Barrette N, Milette S. Enterococcus hirae enteropathy with ascending cholangitis and pancreatitis in a kitten. Vet Pathol. 2000;37(3):282-284.

10. Eich CS, Ludwig LL. The surgical treatment of cholelithiasis in cats: a study of nine cases. J Am Anim Hosp Assoc. 2002;38(3):290-296.

11. Mayhew PD, Holt DE, McLear RC, Washabau RJ. Pathogenesis and outcome of extrahepatic biliary obstruction in cats. J Small Anim Pract. 2002;43(6):247-253.

12. Bacon NJ, White RAS. Extrahepatic biliary tract surgery in the cat. A case series and review. J Small Anim Pract. 2003;44(5):231-235.

13. Pressel MA, Fox LE, Apley MD, Simutis FJ. Vancomycin for multi-drug resistant Enterococcus faecium cholangiohepatitis in a cat. J Feline Med Surg. 2005;7(5):317-321.

14. Buote NJ, Mitchell SL, Penninck D, Freeman LM, Webster CRL. Cholecystoenterostomy for treatment of extrahepatic biliary tract obstruction in cats: 22 cases (1994-2003). J Am Vet Med Assoc. 2006;228(9):1376-1382.

15. Brain PH, Barrs VR, Martin P, Baral R, White JD, Beatty JA. Feline cholecystitis and acute neutrophilic cholangitis: clinical findings, bacterial isolates and response to treatment in six cases. J Feline Med Surg. 2006;8(2):91-103.

16. Mayhew PD, Weisse CW. Treatment of pancreatitisassociated extrahepatic biliary tract obstruction by choledochal stenting in seven cats. J Small Anim Pract. 2008;49(3):133-138.
17. Morrison S, Prostredny J, Roa D. Retrospective study of 28 cases: cholecystoduodenostomy performed with endoscopic gastrointestinal anastomosis stapling equipment. J Am Anim Hosp Assoc. 2008;44(1):10-18.

18. Baker SG, Mayhew PD, Mehler SJ. Choledochotomy and primary repair of extrahepatic biliary duct rupture in seven dogs and two cats. J Small Anim Pract. 2011;52(1):32-37.

19. Twedt DC, Cullen J, McCord K, Janeczko S, Dudak J, Simpson $\mathrm{K}$. Evaluation of fluorescence in situ hybridization for detection of bacteria in feline inflammatory liver disease. J Feline Med Surg. 2014;16(2):109-117.

20. Wagner KA, Hartmann FA, Trepanier LA. Bacterial culture results from liver, gallbladder, or bile in 248 dogs and cats evaluated for hepatobiliary disease: 1998-2003. J Vet Intern Med. 2007;21(3):417-424.

21. Morgan M, Rankin S, Berent A, Weinstein N, Van Winkle T, Rondeau M. Prospective evaluation for bacterial infection in hepatic tissue and bile of cats with diffuse hepatobiliary disease. J Vet Intern Med. 2008;22(3):806. ACVIM Forum Research abstract 342.

22. Morgan M, Rondeau M, Rankin S, et al. A survey of feline inflammatory hepatobiliary disease using the WSAVA classification system. J Vet Intern Med. 2008;22(3):806. ACVIM Forum Research abstract 343.

23. Otte CM, Gutierrez OP, Favier RP, Rothuizen J, Penning LC. Detection of bacterial DNA in bile of cats with lymphocytic cholangitis. Vet Microbiol. 2012;156(1-2):217-221.

24. Keller R, Fischer W, Keist R, Bassetti S. Macrophage response to bacteria: induction of marked secretory and cellular activity by lipoteichoic acids. Infect Immun. 1992;60(9):3664-3672

25. Stinson MW, McLaughlin R, Choi SH, Juarez ZE, Barnard J. Streptococcal histone-like protein: primary structure of hlpA and protein binding to lipoteichoic acid and epithelial cells. Infect Immun. 1998:66(1):259-265.

26. Henneke P, Morath S, Uematsu S, et al. Role of lipoteichoic acid in the phagocyte response to group B streptococcus. J Immunol. 2005;174(10):6449-6455.

27. Tsuneyama K, Harada K, Kono N, et al. Scavenger cells with Gram-positive bacterial lipoteichoic acid infiltrate around the damaged interlobular bile ducts of primary biliary cirrhosis. J Hepatol. 2001;35(2):156-163.

28. Haruta I, Hashimoto E, Kato Y, et al. Lipoteichoic acid may affect the pathogenesis of bile duct damage in primary biliary cirrhosis. Autoimmunity. 2006;39(2):129-135.

29. Haruta I, Hashimoto E, Shibata N, Kato Y, Kobayashi M, Shiratori K. Lipoteichoic acid may affect the pathogenesis of PBC-like bile duct damage and might be involved in systemic multifocal epithelial inflammation in chronic colitis-harboring TCRa-/- x AIM -/- mice. Autoimmunity. 2007;40(5):372-379.

30. Freudenberg MA, Galanos C. Bacterial lipopolysaccharides: structure, metabolism, and mechanisms of action. Int Rev Immunol. 1990;6(4):207-221.

31. Mimura Y, Sakisaka S, Harada, Sata M, Tanikawa K. Role of hepatocytes in direct clearance of lipopolysaccharide in rats. Gastroenterology. 1995;109(6):1969-1976.

32. Szabo G, Bala S, Petrasek J, Gattu A. Gut-liver axis and sensing microbes. Dig Dis. 2010;28(6):737-744.

33. Carotti S, Guarino MPL, Vespasiani-Gentilucci U, Morini $\mathrm{S}$. Starring role of toll-like receptor-4 activation in the gut liver axis. World J Gastrointest Pathophysiol. 2015;6(4):99-109.

34. Soares J-B, Pimentel-Nunes P, Roncon-Alburquerque R Jr, Leite-Moreira A. The role of lipopolysaccharide/toll-like receptor 4 signaling in chronic liver diseases. Hepatol Int. 2010;4(4):659-672.

35. Ravin HA, Rowley D, Jenkins C, Fine J. On the absorption of bacterial endotoxin from the gastro-intestinal tract of the normal and shocked animal. J Exp Med. 1960;112(5):783-792.

36. Wolter J, Liehr H, Grun M. Hepatic clearance of endotoxins: differences in arterial and portal venous infusion. J Reticuloendothe/ Soc. 1978;23(2):145-152. 
37. Freudenberg MA, Kleine B, Galanos C. The fate of lipopolysaccharide in rats: evidence for chemical alteration in the molecule. Rev Infect Dis. 1984;6(4):483-487.

38. Nolan JP. The role of intestinal endotoxin in liver injury: a long and evolving history. Hepatology. 2010;52(5):1829-1835

39. Van den Ingh TSGAM, Cullen JM, Twedt DC, et al. Morphological classification of biliary disorders of canine and feline liver. In: Rothuizen J, Bunch SE, Charles JA, et al, eds. WSAVA Standards for Clinical and Histological Diagnosis of Canine and Feline Liver Disease. Saunders Elsevier; 2006:61-76.

40. Callahan Clark JE, Haddad JL, Brown DC, Morgan MJ, Van Winkle TJ, Rondeau MP. Feline cholangitis: a necropsy study of 44 cats (1986-2008). J Feline Med Surg. 2011;13(8):570-576.

41. Pillai S, Center SA, McDonough SP, et al. Ductal plate malformation in the liver of Boxer dogs: clinical and histological features. Vet Pathol. 2016:53(3):602-613.

42. Seibert LM, Center SA, Randolph JF, et al. Relationships between congenital peritoneopericardial diaphragmatic hernia or congenital central diaphragmatic hernia and ductal plate malformations in dogs and cats. J Am Vet Med Assoc. 2021;259(9):1009-1024.

43. Day MJ, Mansell J, Wilcock B, et al. Histopathologica standards for the diagnosis of gastrointestinal inflammation in endoscopic biopsy samples from the dog and cat: a report from the WSAVA Gastrointestinal Standardization Group. J Comp Pathol. 2008;138(suppl 1):S1-S43.

44. Cebul RD, Hershey JC, Williams SV. Using multiple tests: series and parallel approaches. Clin Lab Med. 1982;2(4):871-890.

45. Byfield VL, Callahan Clark JE, Turek BJ, Bradley CW, Rondeau MP. Percutaneous cholecystocentesis in cats with suspected hepatobiliary disease. J Feline Med Surg. 2017:19(12):1254-1260.

46. Schiborra F, McConnell JF, Maddox TW. Percutaneous ultrasound-guided cholecystocentesis: complications and association of ultrasonographic findings with bile culture results. J Small Anim Pract. 2017;58(7):389-394.

47. Smith RP, Gookin JL, Smolski W, Di Cicco MF, Correa M, Seiler GS. Association between gallbladder ultrasound findings and bacterial culture of bile in 70 cats and 202 dogs. J Vet Intern Med. 2017;31(5):1451-1458.

48. Wells CL, Maddaus MA, Reynolds CM, Jechorek RP, Simmons $\mathrm{RL}$. Role of anaerobic flora in the translocation of aerobic and facultatively anaerobic intestinal bacteria. Infect Immun. 1987;55(11):2689-2694.

49. Brook I. Enhancement of growth of aerobic and facultative bacteria in mixed infections with Bacteroides species. Infect Immun. 1985;50(3):929-931.

50. Brook I. The role of encapsulated anaerobic bacteria in synergistic infections. FEMS Microbiol Rev. 1994;13(1):65-74.

51. Steffen EK, Berg RD, Deitch EA. Comparison of translocation rates of various indigenous bacteria from the gastrointestinal tract to the mesenteric lymph node. J Infect Dis. 1988;157(5):1032-1038.

52. Becerra SC, Roy RC, Sanchez J, Christy RJ, Burmeister DM An optimized staining technique for the detection of Gram positive and Gram negative bacteria within tissue. BMC Res Notes. 2016:9:216. doi:10.1186/s13104-016-1902-0

53. Sung JY, Olson ME, Leung JWC, et al. The sphincter of Oddi is a boundary for bacterial colonisation in the feline biliary tract. Microb Ecol Health Dis. 1990;3(4):199-207.

54. Navaneethan U, Jayanthi V, Mohan P. Pathogenesis of cholangitis in obstructive jaundice-revisited. Minerva Gastroenterol Dietol. 2011;57(1):97-104

55. Sung JY, Leung JW, Olson ME, Lundberg MS, Costerton JW. Demonstration of transient bacterobilia by foreign body implantation in feline biliary tract. Dig Dis Sci. 1991;36(7):943948.

56. Sung JY, Shaffer EA, Olson ME, J W Leung JW, Lam K, Costerton JW. Bacterial invasion of the biliary system by way of the portalvenous system. Hepatology. 1991;14(2):313-317.
57. Suzuki Y, Kobayashi A, Ohto M, et al. Bacteriological study of transhepatically aspirated bile: relation to cholangiographic finding in 295 patients. Dig Dis Sci. 1984;29(2):109-115.

58. Slocum MM, Sittig KM, Specian RD, Deitch EA. Absence of intestinal bile promotes bacterial translocation. Am Surg. 1992;58(5):305-310.

59. Boyer JL. Tight junctions in normal and cholestatic liver: does the paracellular pathway have functional significance? Hepatology. 1983;3(4):614-617.

60. De Vos R, Desmet VJ. Morphologic changes of the junctional complex of the hepatocytes in rat liver after bile duct ligation. Br J Exp Pathol. 1978;59(2):220-227.

61. Katz S, Grosfeld JL, Gross K, et al. Impaired bacterial clearance and trapping in obstructive jaundice. Ann Surg. 1984:199(1):14-20.

62. Tanaka N, Ryden S, Bergqvist L, Christensen P, Bengmark S. Reticulo-endothelial function in rats with obstructive jaundice. Br J Surg. 1985;72(12):946-949.

63. Van Bossuyt H, De Zanger RB, Wisse E. Cellular and subcellular distribution of injected lipopolysaccharide in rat liver and its inactivation by bile salts. J Hepatol. 1988;7(3):325-337.

64. Clemments WD, Parks R, Erwin P, Halliday MI, Barr J, Rowlands BJ. Role of the gut in the pathophysiology of extrahepatic biliary obstruction. Gut. 1996;39(4):587-593.

65. Hofmann AF, Eckmann L. How bile acids confer gut mucosal protection against bacteria. PNAS. 2006;103(12):4333-4334.

66. Mantis NJ, Rol N, Corthesy B. Secretory IgA's complex roles in immunity and mucosal homeostasis in the gut. Mucosal Immunol. 2011;4(6):603-611.

67. Yamada T, Matsuda M, Ashida Y, et al. Isolation of secretory IgA from feline bile and bile IgA levels in growing cats. J Vet Med Sci. 1992;54(4):717-721.

68. Orlans E, Peppard JV, Payne AW, et al. Comparative aspects of the hepatobiliary transport of IgA. Ann N Y Acad Sci. 1983;409(1):411-427.

69. Kocsár LT, Bertók L, Várterész V. Effect of bile acids on the intestinal absorption of endotoxin in rats. $J$ Bacterio/. 1969;100(1):220-223.

70. Inagaki T, Moschetta A, Lee Y-K. Regulation of antibacterial defense in the small intestine by the nuclear bile acid receptor. Proc Natl Acad Sci U S A. 2006;103(10):3920-3925.

71. Green J, Better OS. Systemic hypotension and renal failure in obstructive jaundice-mechanistic and therapeutic aspects. J Am Soc Nephrol. 1995;5(11):1853-1871.

72. Stewart L, Pellegrini CA, Way LW. Cholangiovenous reflux pathways as defined by corrosion casting and scanning electron microscopy. Am J Surg. 1988;155(1):23-28.

73. Raper SE, Barker ME, Jones AL, Way LW. Anatomic correlates of bacterial cholangiovenous reflux. Surgery. 1989:105(3):352-358.

74. Crouch JE. External and internal anatomy of the esophagus, stomach, duodenum and pancreas. In: Text-Atlas of Cat Anatomy. Lea \& Febiger; 1969:144-145.

75. van Brummelen SE, Venneman NG, van Erpecum KJ, VanBerge-Henegouwen GP. Acute idiopathic pancreatitis: does it really exist or is it a myth? Scand J Gastroenterol Suppl. 2003;239:117-122.

76. Elta GH. Sphincter of Oddi dysfunction and bile duct microlithiasis in acute idiopathic pancreatitis. World J Gastroenterol. 2008;14(7):1023-1026.

77. Saraswat VA, Sharma BC, Agarwal DK, Kumar R, Negi TS, Tandon RK. Biliary microlithiasis in patients with idiopathic acute pancreatitis and unexplained biliary pain: response to therapy. J Gastroenterol Hepatol. 2004;19(10):1206-1211.

78. Gerke H, Baillie J. Biliary microlithiasis: a neglected cause of recurrent pancreatitis and biliary colic? J Gastroenterol Hepatol. 2005;20(4):499-501.

79. Venneman NG, Buskens E, Besselink MGH, et al. Small gallstones are associated with increased risk of acute pancreatitis: potential benefits of prophylactic cholecystectomy? Am J Gastroenterol. 2005;100(11):2540-2550.

80. Sheen-Chen S, Chen W, Eng H, et al. Bacteriology and an- 
timicrobial choice in hepatolithiasis. Am J Infect Control. 2000;28(4):298-301.

81. Karpel E, Madej A, Bułdak L, et al. Bile bacterial flora and its in-vitro resistance pattern in patients with acute cholangitis resulting from choledocholithiasis. Scand J Gastroenterol. 2011;46(7-8):925-930.

82. Wang Y, Qi M, Qin C, Hong J. Role of the biliary microbiome in gallstone disease. Exp Rev Gastroenterol Hepatol. 2018;12(12):1193-1205.

83. Son G, Kremer M, Hines IN. Contribution of gut bacteria to liver pathobiology. Gastroenterol Res Pract. 2010;2010:453563. doi:10.1155/2010/453563

84. Harada K, Nakanuma Y. Cholangiopathy with respect to biliary innate immunity. Int J Hepatol. 2012;2012:793569. doi:10.1155/2012/793569

85. Sung JY, Costerton JW, Shaffer EA. Defense system in the biliary tract against bacterial infection. Dig Dis Sci. 1992:37(5):689-696.

86. Tsung A, McCoy SL, Klune JR, Geller DA, Billiar TR, Hefeneider SH. A novel inhibitory peptide of toll-like receptor signaling limits lipopolysaccharide-induced production of inflammatory mediators and enhances survival in mice. Shock. 2007;27(4):364369.

87. Matsumura T, Ito A, Takii T, Hayashi H, Onozaki K. Endotoxin and cytokine regulation of toll-like receptor (TLR) 2 and TLR4 gene expression in murine liver and hepatocytes. J Interferon Cytokine Res. 2000;20(10):915-921.

88. Miranda-Díaz AG, Alonso-Martínez H, Hernández-Ojeda J, Arias-Carvajal O, Rodríguez-Carrizalez AD, Román-Pintos LM. Toll-like receptors in secondary obstructive cholangiopathy. Gastroenterol Res Pract. 2011;2011:265093. doi:10.1155/2011/265093

89. Hiramatsu K, Harada K, Tsuneyama K, et al. Amplification and sequence analysis of partial bacterial 16S ribosomal RNA gene in gallbladder bile from patients with primary biliary cirrhosis. J Hepatol. 2000;33(1):9-18.

90. Liu S, Gallo DJ, Green AM, et al. Role of toll-like receptors in changes in gene expression and NF-kB activation in mouse hepatocytes stimulated with lipopolysaccharide. Infect Immun. 2002;70(7):3433-3442.

91. Nishimura M, Naito S. Tissue-specific mRNA expression profiles of human toll-like receptors and related genes. Biol Pharm Bull. 2005;28(5):886-892.

92. Harris HW, Brady SE, Rapp JH. Hepatic endosomal trafficking of lipoprotein-bound endotoxin in rats. J Surg Res. 2002;106(1):188-195.

93. Fox ES, Thomas P, Broitman SA. Clearance of gut-derived endotoxins by the liver. Release and modification of $3 \mathrm{H}, 14 \mathrm{C}$-lipopolysaccharide by isolated rat Kupffer cells. Gastroenterology. 1989;96(2 pt 1):456-461.

94. Singh R, Bullard J, Kalra M, et al. Status of bacterial colonization, Toll-like receptor expression and nuclear factorkappa $B$ activation in normal and diseased human livers. Clin Immunol. 2011;138(1):41-49.

95. Mencin A, Kluwe J, Schwabe RF. Toll-like receptors as targets in chronic liver diseases. Gut. 2009;58(5):704-720.

96. Liew FY, Xu D, Brint EK, O’Neill LAJ. Negative regulation of toll-like receptor-mediated immune responses. Nat Rev Immunol. 2005;5(6):446-458.

97. Schwabe RF, Seki E, Brenner DA. Toll-like receptor signaling in the liver. Gastroenterology. 2006;130(6):18861900.

98. Sasatomi K, Noguchi K, Sakisaka S, Sata M, Tanikawa K. Abnormal accumulation of endotoxin in biliary epithelial cells in primary biliary cirrhosis and primary sclerosing cholangitis. J Hepatol. 1998;29(3):409-416.

99. Vespasiani-Gentilucci U, Carotti S, Perrone G, et al. Hepatic toll-like receptor 4 expression is associated with portal inflammation and fibrosis in patients with NAFLD. Liver Int. 2015;35(2):569-581.
100. Yan C, Li X-Z, Li B, et al. Expression of Toll-like receptor (TLR) 2 and TLR4 in the livers of mice infected by Clonorchis sinensis. J Infect Dev Ctries. 2015;9(10):1147-1155.

101. Matsushita H, Miyake Y, Takaki A, et al. TLR4, TLR9, and NLRP3 in biliary epithelial cells of primary sclerosing cholangitis: relationship with clinical characteristics. J Gastroenterol Hepatol. 2015;30(3):600-608.

102. Maroni L, Ninfole E, Pinto C, Benedetti A, Marzioni M. Gutliver axis and inflammasome activation in cholangiocyte pathophysiology. Cells. 2020;9(3):736-749.

103. Yokoyama T, Komori A, Nakamura M, et al. Human intrahepatic biliary epithelial cells function in innate immunity by producing IL-6 and IL-8 via the TLR4-NF-kappaB and -MAPK signaling pathways. Liver Int. 2006;26(4):467-476.

104. Webb CB. Evidence-based medicine ultrasound-guided percutaneous cholecystocentesis in the cat. Vet Clin North Am Small Anim Pract. 2020;50(5):1123-1134.

105. Donlan RM, Consterton JW. Biofilms: survival mechanisms of clinically relevant microorganisms. Clin Microbiol Rev. 2002;15(2):167-193.

106. Adcox HE, Vasicek EM, Dwivedi V, Hoang KV, Turner J, Gunn JS. Salmonella extracellular matrix components influence biofilm formation and gallbladder colonization. Infect Immun. 2016;84(11):3243-3251.

107. Gonzalez-Escobedo G, Gunn JS. Gallbladder epithelium as a niche for chronic Salmonella carriage. Infect Immun. 2013;81(8):2920-2930.

108. Swidsinski A, Schlien P, Pernthaler A, et al. Bacterial biofilm within diseased pancreatic and biliary tracts. Gut. 2005;54(3):388-395.

109. Center SA, Randolph JF, Warner KL, et al. The effects of $S$-adenosylmethionine on clinical pathology and redox potential in the red blood cell, liver, and bile of clinically normal cats. J Vet Intern Med. 2005;19(3):303-314.

110. Center SA, Warner KL, Erb HN. Liver glutathione concentrations in dogs and cats with naturally occurring liver disease. Am J Vet Res. 2002;63(8):1187-1197.

111. Li P, Zhang Z, Gong J, Zhang Y, Zhu X. S-adenosylmethionine attenuates lipopolysaccharide-induced liver injury by downregulating the toll-like receptor 4 signal in Kupffer cells. Hepatol Int. 2014;8(2):275-284.

112. Fickert P, Zollner G, Fuchsbichler A, et al. Ursodeoxycholic acid aggravates bile infarcts in bile duct-ligated and mdr2 knockout mice via disruption of cholangioles. Gastroenterology. 2002;123(4):1238-1251.

113. Fickert P, Pollheimer MJ, Silbert D. Differential effects of norUDCA and UDCA in obstructive cholestasis in mice. J Hepatol. 2013;58(6):1201-1208.

114. Wang X, Yang Y, Huycke MM. Risks associated with enterococci as probiotics. Food Res Int. 2020;129:108788. doi:10.1016/j.foodres.2019.108788.

115. Suvorov A. What is wrong with enterococcal probiotics? Probiotics Antimicrob Proteins. 2020;12(1):1-4.

116. Forchielli ML, Walker WA. The role of gut-associated lymphoid tissues and mucosal defense. Br J Nutr. 2005:93(suppl 1):S41-S48.

117. Llewellyn A, Foey A. Probiotic modulation of innate cell pathogen sensing and signaling events. Nutrients. 2017;9(10):1156. doi:10.3390/nu9101156

118. Barlow S, Chesson A, Collins JD, et al. Introduction of a qualified presumption of safety (QPS) approach for assessment of selected microorganisms referred to EFSA. Opinion of the Scientific Committee. EFSA J. 2007;5(12):1-16. doi:10.2903/j.efsa.2007.587

\section{Supplementary Materials}

Supplementary materials are available online at the journal website: avmajournals.avma.org 